\title{
A parameterization of sub-grid particle formation in sulfur-rich plumes for global- and regional-scale models
}

\author{
R. G. Stevens ${ }^{1}$ and J. R. Pierce ${ }^{1,2}$ \\ ${ }^{1}$ Department of Physics and Atmospheric Science, Dalhousie University, Halifax, NS, Canada \\ ${ }^{2}$ Department of Atmospheric Science, Colorado State University, Fort Collins, CO, USA
}

Correspondence to: R. G. Stevens (rgsteven@dal.ca)

Received: 10 July 2013 - Published in Atmos. Chem. Phys. Discuss.: 25 July 2013

Revised: 28 October 2013 - Accepted: 7 November 2013 - Published: 13 December 2013

\begin{abstract}
New-particle formation in the plumes of coal-fired power plants and other anthropogenic sulfur sources may be an important source of particles in the atmosphere. It remains unclear, however, how best to reproduce this formation in global and regional aerosol models with grid-box lengths that are tens of kilometres and larger. Based on the results of the System for Atmospheric Modelling (SAM), a large-eddy simulation/cloud-resolving model (LES/CRM) with online two-moment aerosol sectional (TOMAS) microphysics, we have developed a computationally efficient, but physically based, parameterization that predicts the characteristics of aerosol formed within sulfur-rich plumes based on parameters commonly available in global- and regional-scale models. Given large-scale mean meteorological parameters ((1) wind speed, (2) boundary-layer height and (3) downward shortwave radiative flux), (4) emissions of $\mathrm{SO}_{2}$ and (5) $\mathrm{NO}_{\mathrm{x}}$ from the source, (6) mean background condensation sink, (7) background $\mathrm{SO}_{2}$ and (8) $\mathrm{NO}_{\mathrm{x}}$ concentrations, and (9) the desired distance from the source, the parameterization will predict (1) the fraction of the emitted $\mathrm{SO}_{2}$ that is oxidized to $\mathrm{H}_{2} \mathrm{SO}_{4}$, (2) the fraction of that $\mathrm{H}_{2} \mathrm{SO}_{4}$ that forms new particles instead of condensing onto pre-existing particles, (3) the mean mass per particle of the newly formed particles, and (4) the number of newly formed particles per kilogram $\mathrm{SO}_{2}$ emitted. The parameterization we describe here should allow for more accurate predictions of aerosol size distributions and a greater confidence in the effects of aerosols in climate and health studies.
\end{abstract}

\section{Introduction}

It is well known that the size of atmospheric aerosols strongly impacts the magnitude of their direct radiative effect (Charlson et al., 1992) and their ability to act as cloud condensation nuclei (CCN) (Dusek et al., 2006), thereby increasing cloud reflectivity and lifetime (Albrecht, 1989; Twomey, 1974). The uncertainty in the effects of aerosols dominates the uncertainty in radiative forcing changes (Forster et al., 2007). These aerosols are also known to cause respiratory problems in humans (Dockery et al., 1993), and those particles smaller than $100 \mathrm{~nm}$ in diameter may have greater health impacts than larger particles (Peters et al., 1997). Thus, it is important to understand aerosol number and size for both climate and health.

One of the largest anthropogenic sources of aerosol mass are sulfur-rich plumes (Dentener et al., 2006). Sulfur dioxide $\left(\mathrm{SO}_{2}\right)$ within these plumes can be oxidized by the hydroxyl radical $(\mathrm{OH})$ to form sulfuric acid $\left(\mathrm{H}_{2} \mathrm{SO}_{4}\right)$, which in turn can condense onto pre-existing particles. If $\mathrm{H}_{2} \mathrm{SO}_{4}$ concentrations are high enough, the $\mathrm{H}_{2} \mathrm{SO}_{4}$ will cluster with itself and other condensible gases to nucleate new particles (Kulmala and Kerminen, 2008). This anthropogenic sulfur has a significant effect on particle concentrations globally, particularly in the Northern Hemisphere (Adams and Seinfeld, 2003; Luo and Yu, 2011; Spracklen et al., 2005; Wang and Penner, 2009).

However, the concentrations of $\mathrm{OH}$ are sensitive to $\mathrm{NO}_{\mathrm{x}}$ (nitric oxide $(\mathrm{NO})+$ nitrogen dioxide $\left(\mathrm{NO}_{2}\right)$ ) concentrations, which will vary across a given plume (Lonsdale et al., 2012). Together with the heterogeneity of the condensation sink (approximately proportional to aerosol surface area) within a 
plume, this causes the $\mathrm{H}_{2} \mathrm{SO}_{4}$ concentrations to vary dramatically within a plume. Nucleation and growth rates, which are strong functions of $\mathrm{H}_{2} \mathrm{SO}_{4}$ concentrations, will in turn vary spatially across a plume. Finally, the coagulation sink of these newly formed particles will also be location-dependant in these plumes, which typically have widths of up to tens of kilometres during the first several hundred kilometres of movement. Currently, global- and regional-scale models typically have resolutions of hundreds and tens of kilometres or more, respectively, and are thus unable to accurately resolve the formation and growth of aerosols within these plumes using grid-box averages for chemical concentrations, aerosol concentrations, and meteorological values.

Therefore, these models have typically assumed that some fraction of all anthropogenic $\mathrm{SO}_{2}$ emissions are oxidized to form sulfate $\left(\mathrm{SO}_{4}\right)$ at the sub-grid scale using a single size distribution for all anthropogenic sulfate sources. For instance, the study of Makkonen et al. (2009) used the assumption recommended by the AeroCom emissions inventory (Dentener et al., 2006): the sulfate was emitted into a single log-normal mode with a median radius of $500 \mathrm{~nm}$ and a standard deviation of 2.0. A number of studies (Adams and Seinfeld, 2002, 2003; Pierce and Adams, 2006, 2009; Pierce et al., 2007; Spracklen et al., 2005) have used a bi-modal distribution comprised of a nucleation mode and an accumulation mode with number mean diameters 10 and $70 \mathrm{~nm}$, and geometric standard deviations 1.6 and 2.0. Either 5 or $15 \%$ of the sulfate mass is emitted into the nucleation mode, depending on the study. Yet another approach was used in the study of Yu and Luo (2009): they emitted $5 \%$ of sulfur mass into the aforementioned nucleation mode and condensed the remaining mass onto the existing accumulation-mode particles. As some of the sulfate formed in the plume must condense onto the pre-existing particles that have been entrained into the plume, this approach is, in this way, more realistic than the other assumptions.

While the studies listed above differ in the amount and size of sub-grid sulfate particles, they all assume that these values are constant regardless of the meteorological and chemical characteristics of the emissions plumes. However, several studies have shown that the particle formation in plumes is strongly sensitive to environmental conditions. Yu (2010) showed that differences in temperature and hydroxyl concentrations cause the size and number of aerosol particles to vary seasonally and diurnally. Lonsdale et al. (2012) showed that the number of particles formed within sulfur-rich plumes is strongly dependent on the emission rates of both $\mathrm{SO}_{2}$ and $\mathrm{NO}_{\mathrm{x}}$ from the source. In addition, we have shown in Stevens et al. (2012) that the background aerosol concentrations and the meteorology have strong effects on number and size of aerosol formed within such plumes. However, there is currently no means of representing these dependencies of plume-scale particle formation in global and regional models.
Several global studies have already investigated the sensitivity of global CCN concentrations to the assumptions made regarding sub-grid sulfate formation. Luo and Yu (2011) varied the fraction of emitted sulfate that was emitted into the nucleation mode from 5 to $15 \%$ and found that this increased the $\mathrm{CCN}$ at an assumed supersaturation of $0.2 \%$ $(\mathrm{CCN}(0.2 \%))$ by up to $18 \%$ over source regions. Furthermore, they found that changing the fraction of emitted $\mathrm{SO}_{2}$ converted to sub-grid sulfate from 0 to $5 \%$ changed global boundary-layer $\mathrm{CCN}(0.2 \%)$ by $11 \%$. The earlier studies of Adams and Seinfeld (2003) and Spracklen et al. (2005) used the 10 and $70 \mathrm{~nm}$ mode sub-grid sulfate assumptions described above. Each found that if the fraction of $\mathrm{SO}_{2}$ converted to sub-grid sulfate was changed from 0 to $3 \%$, $\mathrm{CCN}(0.2 \%)$ in polluted areas would double. Adams and Seinfeld (2003) included only sulfate aerosol in their model, and Spracklen et al. (2005) included only sulfate and seasalt aerosol, so this was believed to be an upper limit for this effect. However, the study of Wang and Penner (2009), which included organic matter, black carbon, and dust, varied the fraction of $\mathrm{SO}_{2}$ converted to sub-grid sulfate over a smaller range (0 to $2 \%$ ), and also found that $\mathrm{CCN}(0.2 \%)$ more than doubled over polluted areas. Additionally, they found that $\mathrm{CCN}(0.2 \%)$ increased by 23 to $53 \%$ averaged over global boundary layer and that the aerosol indirect effect radiative forcing increased by 11 to $31 \%$ (depending on the grid-resolved nucleation scheme used in the boundary layer). $\mathrm{CCN}$ concentrations and regional radiative forcings are thus clearly sensitive to the assumptions regarding sulfur partitioning and the size of aerosol formed in sulfur-rich plumes.

Lee et al. (2013) recently quantified the uncertainty in CCN concentrations that was due to 28 different uncertain inputs in the GLOMAP global aerosol model. Based on the results of Stevens et al. (2012), the range of possible values for the diameter of sub-grid sulfate particles used in Lee et al. (2013) was reduced to a smaller range than the full range of sub-grid-sulfate assumptions used previously in studies, which lead to a reduced estimation of the uncertainty in $\mathrm{CCN}$ concentrations attributable to this input compared to the range of estimates described in the previous paragraph. Even with the reduced ranges, the uncertainties in sub-grid $\mathrm{SO}_{4}$ production were found to be just as important as the uncertainties in $\mathrm{SO}_{2}$ emission rates and had the largest contribution of the 28 inputs to the uncertainty in CCN concentrations over polluted North America and Europe. Globally, the uncertainty in sub-grid-sulfate particle size ranked as the twelfth-largest contributor to the relative uncertainties in CCN concentrations of the 28 inputs tested, with a global-mean relative uncertainty range (from -2 to +2 standard deviations in $\mathrm{CCN}$ concentrations) of about $16 \%$. These large uncertainties in $\mathrm{CCN}$ prediction due to sub-grid sulfate formation highlight the need for improved representation of plume-scale particle formation in global and regional models. 
In this paper, we develop a computationally efficient (the increase in running time for a 3-D aerosol model would be negligible because the parameterization consists only of several arithmetic equations), but physically based, parameterization that predicts the characteristics of aerosol formed within sulfur-rich plumes based on parameters commonly available in global- and regional-scale models. This parameterization is based on the results of the System for Atmospheric Modelling (SAM) (Khairoutdinov and Randall, 2003), a large-eddy simulation/cloud-resolving model (LES/CRM) with online two-moment aerosol sectional (TOMAS) microphysics (Adams and Seinfeld, 2002) that has been tested against aircraft observations of particle formation in plumes (Lonsdale et al., 2012; Stevens et al., 2012). Given large-scale mean meteorological parameters ((1) wind speed, $v_{g}\left[\mathrm{~m} \mathrm{~s}^{-1}\right]$, (2) boundary-layer height, BLH [m], and (3) downward shortwave radiative flux, DSWRF [W m$\left.\left.{ }^{-2}\right]\right),(4)$ emissions of $\mathrm{SO}_{2}, \mathrm{SO}_{2}$ emis $\left[\mathrm{kg} \mathrm{s}^{-1}\right]$, and (5) $\mathrm{NO}_{\mathrm{x}}, \mathrm{NO}_{\mathrm{x}}$ emis $\left[\mathrm{kg} \mathrm{N} \mathrm{s}^{-1}\right]$, from the source; (6) mean background condensation sink, $\mathrm{CS}\left[\mathrm{s}^{-1}\right]$; (7) mean background $\mathrm{SO}_{2}, \mathrm{bgSO}_{2}$ [ppb], and (8) $\mathrm{NO}_{\mathrm{x}}, \mathrm{bgNO}_{\mathrm{x}}$ [ppb], concentrations; and (9) the desired distance from the source, $d$ [m]; the predicting particle production in power-plant plumes (P6) parameterization predicts (1) the fraction of the emitted $\mathrm{SO}_{2}$ that is oxidized to form $\mathrm{H}_{2} \mathrm{SO}_{4}, f_{\mathrm{ox}}$; (2) the fraction of that $\mathrm{H}_{2} \mathrm{SO}_{4}$ that forms new particles instead of condensing onto pre-existing particles, $f_{\text {new }}$; (3) the mean mass per particle of the newly formed particles, $M_{\mathrm{m}}[\mathrm{kg}]$; and (4) the number of newly formed particles per mass of $\mathrm{SO}_{2}$ emitted, $N_{\text {new }}$ [\# $\mathrm{kg}^{-1} \mathrm{SO}_{2}$ ].

In Sect. 2 we provide a brief description of the SAMTOMAS model and how the P6 training data were selected. Section 3 describes the form and physical basis of the P6 parameterization. The evaluation of the P6 parameterization against the full SAM-TOMAS model is presented in Sect. 4. We describe sensitivity studies performed using the parameterization in Sect. 5. Finally, we present our conclusions in Sect. 6.

\section{Description of SAM-TOMAS model and training data}

A full description of the SAM-TOMAS model is available in Stevens et al. (2012), so we will restrict ourselves to a brief summary here. The SAM model (Khairoutdinov and Randall, 2003) is a flexible LES/CRM model with a resolution of tens of metres to several kilometres and a domain that can span tens to hundreds of kilometres. The TOMAS microphysics algorithm (Adams and Seinfeld, 2002; Pierce and Adams, 2009) in SAM resolves aerosol by both mass and number independently in 15 size bins spanning 3 to $10 \mu \mathrm{m}$. Condensation, coagulation, and nucleation are explicitly resolved in the model. Sulfate, ammonium $\left(\mathrm{NH}_{3}\right)$, aerosol water, and the gas-phase concentrations of $\mathrm{SO}_{2}, \mathrm{NO}_{\mathrm{x}}$, ammonia $\left(\mathrm{NH}_{4}\right)$, and $\mathrm{H}_{2} \mathrm{SO}_{4}$ are simulated within the model, but secondary organic aerosol formation is not explicitly simulated under the assumption that sulfate aerosol formation will dominate within sulfur-rich plumes.

The concentration of $\mathrm{OH}$ in the SAM-TOMAS model is currently parameterized based on the downward shortwave radiative flux (DSWRF) and the concentration of $\mathrm{NO}_{\mathrm{x}}$. This $\mathrm{OH}$ parameterization is an empirical fit to results from the detailed time-dependent photochemical box model described by Olson et al. (2006). However, the uncertainties associated with the parameterized $\mathrm{OH}$ become large for solar zenith angles larger than $70^{\circ}$, which, for clear-sky conditions, correspond to DSWRF values less than $350 \mathrm{~W} \mathrm{~m}^{-2}$. In addition, we do not account for nitrous acid (HONO) or sulfur trioxide $\left(\mathrm{SO}_{3}\right)$ emission, which may account for additional sulfuric acid formation. Both of these emissions may result in particle formation early in the plume, and may account for the under-prediction of particles within $5 \mathrm{~km}$ of the stack in Stevens et al. (2012). However, we note that these processes do not seem to be necessary to accurately predict particle size and number concentrations beyond $30 \mathrm{~km}$ from the source. When these processes become better understood, we plan to incorporate them into a future version of the P6 parameterization.

During cloudy conditions, $\mathrm{SO}_{2}$ may undergo aqueous oxidation through reaction with $\mathrm{H}_{2} \mathrm{O}_{2}$ or other species (Zhou et al., 2012). Currently, this is not accounted for in the SAMTOMAS model. Therefore, $\mathrm{SO}_{2}$ oxidation is likely underestimated under cloudy conditions. Under such conditions, however, less new-particle formation is expected because DSWRF and subsequently oxidation of $\mathrm{SO}_{2}$ though reaction with $\mathrm{OH}$ will also be suppressed. Also, the additional surface area from cloud droplets in the clouds and cloud-processed aerosols outside of the clouds will slow nucleation and increase coagulational losses of new particles. We therefore do not believe that this would be a significant uncertainty for predicting the number and size of aerosol formed in sulfurrich plumes.

For this study, the model was operated as a Lagrangian 2-D wall model that passed over the power plant after a spin-up period of $1800 \mathrm{~s}$ of model time. The wall extends upwards and horizontally perpendicular to the direction of the mean boundary-layer wind. We have evaluated the model operating in Lagrangian mode against the Eulerian mode used in Stevens et al. (2012), and we have found that the discrepancies in $\mathrm{NO}_{\mathrm{x}}$ and $\mathrm{SO}_{2}$ concentrations between the two models are less than one standard deviation of the concentrations (due to variability in time). Similarly, the total particle concentration within the plume differed by less than $16 \%$ between the Lagrangian and the Eulerian modes, and the particle size distributions had similar characteristics in both models. Both models compare similarly well to the measurements shown in Stevens et al. (2012).

In the simulations used here, the model resolution was held fixed at $400 \mathrm{~m} \times 400 \mathrm{~m} \times 40 \mathrm{~m}$ and the model domain was $120 \mathrm{~km}$ wide and $5 \mathrm{~km}$ high. We chose an empirical 
activation-type nucleation scheme (Kulmala et al., 2006), where nucleation rates are calculated as $10^{-7} \mathrm{~s}^{-1} \cdot\left[\mathrm{H}_{2} \mathrm{SO}_{4}\right]$ because this scheme provided the best match to observations out of the six schemes tested in Stevens et al. (2012). We note that it is clear that such an empirical scheme will not capture all of the variability in nucleation rates. However, an increase in the nucleation rate by a factor of 10 was found in Stevens et al. (2012) to increase $N_{\text {new }}$ by a factor of about 3 for distances greater than $30 \mathrm{~km}$ from the source, and we will show that values of $N_{\text {new }}$ span six orders of magnitude across the set of training data used for this study. As more accurate parameterizations of nucleation become available, we plan to integrate them into SAM-TOMAS and incorporate the results into future versions of the $\mathrm{P} 6$ parameterization.

In order to determine the best-fit parameters for the P6 parameterization, we performed many simulations using the SAM-TOMAS model using a realistic range of different inputs for the emissions, meteorology, and background aerosol and trace gas concentrations. In order to choose realistic, but sufficiently diverse, conditions for the simulations, we performed the procedure described in the following three paragraphs.

To generate a data set of realistic aerosol size distributions and trace gas concentrations, we used output from the GEOS-Chem-TOMAS model. GEOS-Chem-TOMAS uses the TOMAS aerosol microphysics module described above in the GEOS-Chem chemical transport model (www. geos-chem.org; Bey et al., 2001). The implementation of TOMAS in GEOS-Chem has been discussed previously (Pierce et al., 2013; Snow-Kropla et al., 2011; Trivitayanurak et al., 2008). Variables were output every $3 \mathrm{~h}$. The model resolution was $0.5^{\circ} \times 0.666^{\circ}$. We used Latin hypercube sampling (a method of pseudo-randomly choosing a set of samples from a multi dimensional space such that the full range of each dimension is sampled, but the coordinates in each dimension are uncorrelated) to determine a set of 5000 (1) latitudes, (2) longitudes, (3) dates and times, (4) distances from the emissions source (d), (5) emissions rates of $\mathrm{SO}_{2}$ ( $\mathrm{SO}_{2}$ emis) and (6) $\mathrm{NO}_{\mathrm{x}}\left(\mathrm{NO}_{\mathrm{x}}\right.$ emis), and (7) effective emissions heights, which implicitly includes both the height of the emissions stack and the initial buoyant rise of the plume. The range of values used for each of these variables is listed in Table 1. We note that while only the month of July was sampled to create the training data, the large geographic range used provided diverse meteorological conditions. As the $\mathrm{OH}$ parameterization used in the SAM-TOMAS model has high uncertainties for large solar zenith angles, we excluded the hours of 03:00, 06:00, and 09:00 UTC from our range of times to be selected as these should be at high solar zenith angles or outside daylight hours for the latitude and longitude range we selected. In order to further reduce the number of cases with high solar zenith angles, we subsequently excluded from our analysis any cases that had DSWRF values less than $100 \mathrm{~W} \mathrm{~m}^{-2}$. We then obtained the background aerosol size distribution, background $\mathrm{SO}_{2}$
Table 1. Parameter space used to create training data for the P6 parameterization.

\begin{tabular}{lll}
\hline $\begin{array}{l}\text { Parameter } \\
\text { Latitude } \\
\text { Longitude }\end{array}$ & Minimum & Maximum \\
$30^{\circ} \mathrm{N}$ & $70^{\circ} \mathrm{N}$ \\
$55^{\circ} \mathrm{W}$ & $110^{\circ} \mathrm{W}$ \\
\hline Time & 1 July 2010, & 28 July 2010, \\
& $15: 00 \mathrm{UTC}$ & $21: 00 \mathrm{UTC}$ \\
Distance from source & $5 \mathrm{~km}$ & $100 \mathrm{~km}$ \\
$\left.\log _{10}\left(\mathrm{SO}_{2} \mathrm{emis}^{-1} \mathrm{~kg} \mathrm{~s}^{-1}\right]\right)$ & -3 & 1 \\
$\log _{10}\left(\mathrm{NO}_{\mathrm{x}}\right.$ emis $\left.\left[\mathrm{kg} \mathrm{N} \mathrm{s}^{-1}\right]\right)$ & -3 & 0.3 \\
Emissions height & $60 \mathrm{~m}$ & $580 \mathrm{~m}$ \\
\hline
\end{tabular}

and $\mathrm{NO}_{\mathrm{x}}$ concentrations $\left(\mathrm{bgSO}_{2}\right.$ and $\left.\mathrm{bgNO}_{\mathrm{x}}\right)$, and DSWRF from the GEOS-Chem-TOMAS output that corresponded to each set of latitude, longitude, date, and time. The maximum, minimum, and median values of these outputs from GEOSChem-TOMAS are shown in Table 2.

To drive the dynamics in SAM-TOMAS, we obtained for each set of latitude, longitude, date, and time (1) the corresponding profiles of potential temperature, water vapour mixing ratio, wind speed and direction; (2) the surface fluxes of sensible heat, latent heat, and momentum; and (3) the boundary-layer height (BLH) and the surface pressure from the National Center for Environmental Prediction (NCEP) North American Regional Reanalysis (NARR) (Mesinger et al., 2006) assimilated meteorology data, as was done for the study of Stevens et al. (2012). The reanalysis data were provided by the National Oceanic and Atmospheric Administration (NOAA), Ocean and Atmospheric Research (OAR), Earth System Research Laboratory (ESRL) Physical Sciences Division (PSD) (Boulder, Colorado, USA) from their website at: http://www.esrl.noaa.gov/psd/. The NCEP NARR data were chosen for this study because the software necessary to create input files from reanalysis data was readily available. We note that while the meteorology from the reanalysis data may not correspond exactly to the data from the GEOS-Chem-TOMAS model due to differences in spatial and temporal resolution, an exact match is not necessary to create a realistic set of training inputs.

For each simulation using the SAM-TOMAS model, we used $\mathrm{SO}_{2}$ emis, $\mathrm{NO}_{\mathrm{x}}$ emis, and effective emissions height from the Latin hypercube sample; the background aerosol size distribution, $\mathrm{bgSO}_{2}, \mathrm{bgNO}_{\mathrm{x}}$, and DSWRF from the output of the GEOS-Chem-TOMAS model; and the SAMTOMAS meteorology that was driven by nudging and boundary conditions from the NCEP-NARR assimilated meteorology data. We ran the model until the emissions reached the distance from the source specified from the Latin hypercube sample. We preserved the following variables as training inputs for the P6 parameterization: (1) $\mathrm{SO}_{2}$ emis, (2) $\mathrm{NO}_{\mathrm{x}} \mathrm{emis}$, (3) total condensation sink of the background aerosol size distribution (CS), (4) DSWRF, (5) the mean wind speed 
Table 2. Outputs from GEOS-Chem-TOMAS used as inputs for SAM-TOMAS. The fully resolved aerosol size distribution from GEOS-Chem-TOMAS was used in SAM-TOMAS, but for conciseness we only tabulate the condensation sink here. Cases where the DSWRF was less than 100 were excluded from this study because of uncertainties associated with $\mathrm{OH}$ production for these conditions.

\begin{tabular}{|c|c|c|c|}
\hline Parameter & Minimum & Maximum & Median \\
\hline Condensation sink $\left[\mathrm{s}^{-1}\right]$ & $8.94 \times 10^{-5}$ & $1.46 \times 10^{-2}$ & $1.38 \times 10^{-3}$ \\
\hline Background $\mathrm{SO}_{2}$ [ppb] & $1.27 \times 10^{-6}$ & 16.6 & 0.0707 \\
\hline Background $\mathrm{NO}_{\mathrm{x}}[\mathrm{ppb}]$ & $2.84 \times 10^{-4}$ & 7.93 & 0.0302 \\
\hline DSWRF $\left[\mathrm{W} \mathrm{m}^{-2}\right]$ & 100 & 960 & 401 \\
\hline
\end{tabular}

Table 3. Minimum, maximum, and median values of the mean boundary-layer wind speeds and the boundary-layer heights for the training data used in this study.

\begin{tabular}{llll}
\hline Parameter & Minimum & Maximum & Median \\
\hline Wind speed $\left[\mathrm{m} \mathrm{s}^{-1}\right]$ & 0.178 & 26.1 & 5.98 \\
Boundary-layer height [m] & 53 & 2792 & 434 \\
\hline
\end{tabular}

within the boundary layer $\left(v_{g}\right),(6) \mathrm{BLH},(7)$ the distance from the source $(d),(8) \mathrm{bgSO}_{2}$, and (9) $\mathrm{bgNO}_{\mathrm{x}}$. The maximum and minimum values of these parameters are shown in Tables 1, 2, and 3. Other information necessary to run the SAM-TOMAS model - such as the effective emissions height, the potential temperature profile, the water vapour mixing ratio profile, and the surface fluxes - may not be available in many regional- and global-scale models and the current P6 inputs capture most of the variability in aerosol formation and growth within plumes, as we will show in Sect. 5. We have therefore excluded them as inputs to the parameterization. However, by including a wide range of these conditions in the simulations used to fit the parameterization, we hope to exclude a possible bias in our predictions, and to have a more realistic assessment of the accuracy of the parameterization.

\section{Description of the parameterization}

The purpose of the P6 parameterization is to predict the fraction of emitted $\mathrm{SO}_{2}$ that is oxidized in the plume $\left(f_{\mathrm{ox}}\right)$, whether or not a significant number of new particles are nucleated, the number of new particles nucleated per $\mathrm{kg} \mathrm{SO}_{2}$ emitted $\left(N_{\text {new }}\right.$, [\#/kg SO 2$\left.]\right)$, the mean mass per particle of the new particles $\left(M_{\mathrm{m}},[\mathrm{kg}]\right)$, and the fraction of the $\mathrm{H}_{2} \mathrm{SO}_{4}$ formed within the plume that comprises new particles $\left(f_{\text {new }}\right)$.

As inputs to the parameterization, we have chosen variables that are commonly available in global- and regionalscale models: the source-level $\mathrm{SO}_{2}$ and $\mathrm{NO}_{\mathrm{x}}$ emissions $\left(\mathrm{SO}_{2} \mathrm{emis}\left[\mathrm{kg} \mathrm{s}^{-1}\right]\right.$ and $\mathrm{NO}_{\mathrm{x}}$ emis $\left.\left[\mathrm{kg} \mathrm{N} \mathrm{s}^{-1}\right]\right)$, the downward shortwave radiative flux at the surface (DSWRF $\left[\mathrm{W} \mathrm{m}^{-2}\right]$ ), the background aerosol condensation sink ( $\mathrm{CS}\left[\mathrm{s}^{-1}\right]$ ), the
Table 4. Emissions rates for coal-fired power plants in the USA from the 2010 EPA CAM data. "Medium" emissions are defined as the log-space mean, "high" as one standard deviation above the mean, and "low" as one standard deviation below the mean.

\begin{tabular}{lll}
\hline & $\mathrm{SO}_{2}$ & $\mathrm{NO}_{\mathrm{x}}$ \\
\hline high & $1.00 \mathrm{~kg} \mathrm{~s}^{-1}$ & $0.290 \mathrm{~kg} \mathrm{~s}^{-1}$ \\
medium & $0.202 \mathrm{~kg} \mathrm{~s}^{-1}$ & $0.0840 \mathrm{~kg} \mathrm{~s}^{-1}$ \\
low & $0.0606 \mathrm{~kg} \mathrm{~s}^{-1}$ & $0.0300 \mathrm{~kg} \mathrm{~s}^{-1}$ \\
\hline
\end{tabular}

boundary-layer height (BLH $[\mathrm{m}])$, the mean wind speed in the boundary layer $\left(v_{g}\left[\mathrm{~m} \mathrm{~s}^{-1}\right]\right)$, the distance from the source $(d[\mathrm{~m}])$ at which the plume is considered mixed with the model grid boxes, and the background $\mathrm{SO}_{2}$ and $\mathrm{NO}_{\mathrm{x}}$ concentrations ( $\mathrm{bgSO}_{2}[\mathrm{ppb}]$ and $\left.\mathrm{bgNO}_{\mathrm{x}}[\mathrm{ppb}]\right)$. We will consistently use the given units for all inputs and outputs in all of the following equations.

Often, emissions inventories provide $\mathrm{SO}_{2}$ and $\mathrm{NO}_{\mathrm{x}}$ emissions within each box on a given grid, instead of associated with particular sources specifically. Therefore, it may not be known how many power plants are responsible for the emissions in a given grid box. We therefore allow the P6 parameterization to be operated in the following ways: (1) by default, it is assumed that the emissions of each anthropogenic sulfur-rich point source are known individually, in which case $f_{\text {ox }}, N_{\text {new }}, M_{\mathrm{m}}$, and $f_{\text {new }}$ will be predicted for each source plume individually. (2) If instead the total emissions of $\mathrm{SO}_{2}$ and $\mathrm{NO}_{\mathrm{x}}$ from sulfur-rich sources within a given area (but not the individual sources within that area) are known, the P6 parameterization will provide outputs based on the assumption that the emissions for the sources are divided between an equal number of high, medium, and low emitters. We define high, medium, and low emitters based on the emissions data for power plants in the United States compiled from the Clean Air Markets (CAM) data (United States Environmental Protection Agency, 2012) as follows: for medium emitters, we use the log-space mean emission rates for a power plant in the USA during 2010. For low and high emitters, we use an emission rate that is one standard deviation below or above the mean in log space, respectively. The high, medium, and low emission rates are listed in Table 4. (3) If the $\mathrm{SO}_{2}$ emissions are known, but the $\mathrm{NO}_{\mathrm{x}}$ emissions are not known (or the $\mathrm{NO}_{\mathrm{x}}$ emissions from the major $\mathrm{SO}_{2}$ sources are not known), the median $\mathrm{SO}_{2}: \mathrm{NO}_{\mathrm{x}}$ emissions ratio of 0.419 from the 2010 EPA CAM data will be assumed (as well as the high-, medium-, and low-emitter assumptions from the previous P6 mode).

Even if the precise locations of power plants are known, it may not be clear at what distance from the source the particles are well mixed within a grid box that also contains the source of emissions. However, as we will show in Sect. 5, the P6 values of $M_{\mathrm{m}}, N_{\text {new }}$, and $f_{\text {new }}$ are not strongly sensitive to the distance from the source beyond distances of $30 \mathrm{~km}$, 
Table 5. Emission scaling factors used in the P6 parameterization for determining effective $\mathrm{SO}_{2}$ and $\mathrm{NO}_{\mathrm{x}}$ concentrations (Eqs. 1 and 9).

\begin{tabular}{|c|c|c|}
\hline & $\begin{array}{l}\mathrm{NO}_{\mathrm{X}} \text { emis } \\
\text { scaling factor }\end{array}$ & $\begin{array}{l}\mathrm{SO}_{2} \text { emis } \\
\text { scaling factor }\end{array}$ \\
\hline $\begin{array}{l}\text { In-plume mean } \\
\text { concentration }\end{array}$ & $9.595 \times 10^{4}$ & $1.705 \times 10^{4}$ \\
\hline$f_{\text {ox }}$ & $1.444 \times 10^{-8}$ & - \\
\hline nucleation & $4.365 \times 10^{5}$ & $2.239 \times 10^{4}$ \\
\hline$M_{\mathrm{m}}$ & $2.139 \times 10^{7}$ & $2.605 \times 10^{6}$ \\
\hline$N_{\text {new }}$ & $1.243 \times 10^{6}$ & - \\
\hline
\end{tabular}

and $f_{\text {ox }}$ depends less than linearly on the distance from the source.

In the following subsections, we describe the theory and semi-empirical fits behind the P6 parameterization.

\subsection{Fraction oxidized}

In order to formulate a semi-empirical equation for $f_{\text {ox }}$, we first formulate a semi-empirical equation for the effective $\mathrm{NO}_{\mathrm{x}}$ mixing ratio within the plume because $\mathrm{NO}_{\mathrm{x}}$ modulates the $\mathrm{OH}$ concentrations and thus affects the oxidation rate of $\mathrm{SO}_{2}$. The mean concentration of $\mathrm{NO}_{\mathrm{x}}$ within the plume should be equal to the sum of the contributions from the background and the emitted $\mathrm{NO}_{\mathrm{x}}$ after accounting for dilution, which should be related to $v_{g}, \mathrm{BLH}$, and the time since emission, calculated as $\left(d / v_{g}\right)$. We therefore calculate the effective $\mathrm{NO}_{\mathrm{x}}$ concentration, $\mathrm{NO}_{\mathrm{x}, \text { eff }}$ [ppb], as

$\mathrm{NO}_{\text {xeff }}=\operatorname{bgNO}_{\mathrm{x}}+1.444 \times 10^{-8} \frac{\mathrm{NO}_{\mathrm{x}} \mathrm{emis}}{v_{g}^{1.234} \mathrm{BLH}^{0.2018}\left(\frac{d}{v_{g}}\right)^{0.7902}}$,

where the exponents for $v_{g}$, BLH, and $\left(d / v_{g}\right)$ have been fitted for this equation to the average concentrations of $\mathrm{NO}_{\mathrm{x}}$ in the plume using the training data (evaluation of the fit in Sect. 4). We allowed the scaling factor of $1.444 \times 10^{-8}$ to be freely fitted to the data because the relative importance of the background concentrations and the emitted $\mathrm{NO}_{\mathrm{x}}$ is different for the $f_{\mathrm{ox}}$ than it is for the mean concentration of $\mathrm{NO}_{\mathrm{x}}$. As the relative importance of background and emitted $\mathrm{NO}_{\mathrm{x}}$ is also different for determining nucleation, $M_{\mathrm{m}}$, and $N_{\text {new }}$, we list the scaling factors used to calculate $\mathrm{NO}_{\mathrm{x}, \text { eff }}$ for each of these outputs in Table 5. The scaling factor found when fitting to the mean $\mathrm{NO}_{\mathrm{x}}$ concentration within the plume was $9.595 \times 10^{4}$. However, the best-fit scaling factor found for calculating $f_{\mathrm{ox}}$ is much lower, such that the $\mathrm{NO}_{\mathrm{x} \text {,eff }}$ is dominated by $\mathrm{bNO}_{\mathrm{x}}$. Generally, $\mathrm{NO}_{\mathrm{x}}$ concentrations are sufficiently high within the centre of the plume (and early in the plume) to prevent fast oxidation of $\mathrm{SO}_{2}$, so the background concentrations are relatively much more important to $f_{\text {ox }}$ than they are to the mean $\mathrm{NO}_{\mathrm{x}}$ concentration within the plume.
We calculate an effective $\mathrm{OH}$ concentration using the same parameterization that is used in the SAM-TOMAS model. This parameterization calculates the $\mathrm{OH}$ concentration as a function of the $\mathrm{NO}_{\mathrm{x}}$ concentration within the plume and the DSWRF. The parameterization, which is a fit of chemistry box-model simulations of Olson et al. (2006), was originally described in Appendix A of Stevens et al. (2012).

First, we set variables $x$ and $y$ :

$x=\log \left(\mathrm{NO}_{\mathrm{x}, \mathrm{eff}}\right)-0.195$,

$y=\frac{\mathrm{DSWRF}}{S_{0} \cdot T}$,

where $S_{0}$ is the solar constant at the top of the atmosphere, $1370 \mathrm{~W} \mathrm{~m}^{-2}$, and $T$ is an assumed transmittance of the clear atmosphere, 0.76. We then calculate two polynomials, the first (P1) estimating the shape of the $\mathrm{OH}$ versus $\mathrm{NO}_{\mathrm{x}}$ relationship, and the second (P2) capturing the dependance of $\mathrm{OH}$ on DSWRF:

$$
\begin{aligned}
& P 1=-0.014 x^{6}+0.0027 x^{5}+0.1713 x^{4}-0.0466 x^{3} \\
& -0.7893 x^{2}-0.1739 x+6.9414, \\
& P 2=\left(-1345 y^{3}+4002 y^{2}-471.8 y+42.72\right) \times 10^{4} .
\end{aligned}
$$

From $\mathrm{P} 1$ and $\mathrm{P} 2$, we calculate the effective $\mathrm{OH}$ concentration, $\mathrm{OH}_{\mathrm{eff}}$, [molec $\left.\mathrm{cm}^{-3}\right]$ :

$\mathrm{OH}_{\text {eff }}=0.82 \cdot 10^{\mathrm{P} 1 \cdot \log (\mathrm{P} 2) / 6.8}$.

If we assume that the only loss mechanism for $\mathrm{SO}_{2}$ is through reaction with $\mathrm{OH}$ (e.g. clear skies and ignore reactions with Criegee intermediates; Mauldin et al., 2012), and we knew the true $\mathrm{OH}$ concentrations, we could calculate $f_{\text {ox }}$ by using the rate constant $k$, the time elapsed $t$, and the following equation:

$f_{\mathrm{ox}}=1-\exp (-k[\mathrm{OH}] t)$.

However, given that $O H_{\text {eff }}$ is not the true concentration, and that we must calculate $t$ as $d / v_{g}$, we use the analogous equation

$f_{\mathrm{ox}}=1-\exp \left(-1.650 \times 10^{-10} \mathrm{OH}_{\mathrm{eff}}^{0.7904}\left(\frac{d}{v_{g}}\right)^{0.7723}\right)$,

where the numerical values have been selected by minimizing the error between the P6 fit $f_{\text {ox }}$ values and the predicted $f_{\text {ox }}$ from the SAM-TOMAS simulations. As the bestfit $\mathrm{NO}_{\mathrm{x}}$ emis scaling factor for calculation of $\mathrm{NO}_{\mathrm{x}, \mathrm{eff}}$ is near zero, $\mathrm{OH}_{\text {eff }}$ is approximately equal to the $\mathrm{OH}$ concentration outside of the plume in the $f_{\mathrm{ox}}$ calculation. $\mathrm{NO}_{\mathrm{x}}$ concentrations will generally be high enough within the plume for $\mathrm{OH}$ concentrations within the plume to be less than the $\mathrm{OH}$ concentrations at the plume edges, and therefore the best fit exponent for $\mathrm{OH}_{\text {eff }}$ is less than one. Oxidation of $\mathrm{SO}_{2}$ subsequently proceeds more slowly within the plume than at the edges, and thus the best-fit exponent for $\left(d / v_{g}\right)$ is also less than 1 . 


\subsection{Nucleation}

In order to determine whether or not significant nucleation occurs within the plume, we first calculate the effective $\mathrm{NO}_{\mathrm{x}}$ and $\mathrm{SO}_{2}$ concentrations within the plume. The effective $\mathrm{SO}_{2}$ concentration, $\mathrm{SO}_{2, \text { eff }}[\mathrm{ppb}]$, is defined similarly to $\mathrm{NO}_{\mathrm{x}, \text { eff }}$ as

$\mathrm{SO}_{2 \text { eff }}=\operatorname{bgSO}_{2}+2.239 \times 10^{4} \frac{\mathrm{SO}_{2} \text { emis }}{v_{g}^{1.229} \mathrm{BLH}^{0.1891}\left(\frac{d}{v_{g}}\right)^{0.7732}}$,

where the exponents for $v_{g}$, BLH, and $\left(d / v_{g}\right)$ have been fitted for this equation to the average concentration of $\mathrm{SO}_{2}$ in the plume. The scaling factor found when fitting to the mean $\mathrm{SO}_{2}$ concentration within the plume was $1.705 \times 10^{4}$. The scaling factors for $\mathrm{SO}_{2 \text { eff }}$ and $\mathrm{NO}_{\mathrm{x}, \text { eff }}$ for determining nucleation are $2.239 \times 10^{4}$ and $4.365 \times 10^{5}$, respectively, as listed in Table 5.

We then calculate nucp, our predictor for whether nucleation is likely, from the following equation:

nucp $=\frac{\left(\mathrm{SO}_{2, \mathrm{eff}}\right)^{1.92} \mathrm{dswrf}^{3.28}}{\left(\mathrm{NO}_{\mathrm{x}, \mathrm{eff}}\right)^{1.24} \mathrm{CS}^{3.48}}$.

We compare the value of nucp to $2.988 \times 10^{14}$. If it is smaller, then we predict that nucleation is slow and that any particles that are formed within the plume will be quickly lost to coagulation: there will be no net increase in particle number within the plume. If it is larger, we predict that significant new-particle formation will occur. This test is accurate for $95.8 \%$ of our training cases. For those cases where nucleation is falsely predicted or falsely not predicted, the maximum P6 or SAM-TOMAS values of $M_{\mathrm{m}}$, respectively, were less than the median values of $M_{\mathrm{m}}$ for the full set of training data. The maximum number of new particles formed was similarly lower than the median for the full set of training data. Particle formation rates and growth rates were therefore typically lower for the cases where this test was incorrect than for the correctly predicted cases.

\subsection{Mean mass per particle of new particles}

If we predict that there will be significant nucleation, we then predict the mean mass per particle of the newly formed particles. We expect that the particles will be growing primarily through condensation of available $\mathrm{H}_{2} \mathrm{SO}_{4}$. Therefore, we expect that the mean mass per particle, $M_{\mathrm{m}}$, will be proportional to the product of the time elapsed $\left(d / v_{g}\right), f_{\text {ox }}$, and $\mathrm{SO}_{2 \text { eff. }}$. Since the pre-existing particles will be competing for the available $\mathrm{H}_{2} \mathrm{SO}_{4}$, we divide this value by the background condensation sink, CS, the first-order rate constant of the loss of condensible vapour by condensation, which is proportional to the Fuchs-corrected surface area of the particles (Kerminen et al., 2004). We add a constant minimum value to this, which corresponds to the smallest size of aerosol that can be resolved by the SAM-TOMAS model. In this way we arrive at the following equation for $M_{\mathrm{m}}$ :

$M_{\mathrm{m}}=1.475 \times 10^{-27} \frac{f_{\mathrm{ox}}^{1.517} \mathrm{SO}_{2, \mathrm{eff}}^{1.094}}{\mathrm{CS}^{0.6173}}\left(\frac{d}{v_{g}}\right)^{0.9685}+4.071 \times 10^{-23} \mathrm{~kg}$.

Again, we include the fitted parameters in this equation, and the fit will be evaluated in Sect. 4 .

However, we note that the free parameters for predicting $f_{\text {ox }}$ were optimized to reduce the root-mean-square (rms) absolute error between the parameterized $f_{\text {ox }}$ and the SAMTOMAS predicted $f_{\text {ox }}$ to a minimum, and we are more interested in minimizing the rms relative error in $M_{\mathrm{m}}$, since $M_{\mathrm{m}}$ spans several orders of magnitude. We therefore allowed the free parameters used to predict $f_{\text {ox }}$ to change when we sought the parameters that minimize the rms error in $\log _{10}\left(M_{\mathrm{m}}\right)$. Notably, the $\mathrm{NO}_{\mathrm{x}}$ emis scaling factor (Eq. (1)) used within the calculation of $M_{\mathrm{m}}$ is several orders of magnitude larger than that used within the calculation of $f_{\text {ox }}$, as listed in Table 5. We will discuss this difference further in Sect. 5 .

We can calculate the mass mean diameter $D_{\text {mass }}[\mu \mathrm{m}]$ as

$D_{\text {mass }}=\left(\frac{M_{\mathrm{m}}}{\rho} \frac{6}{\pi}\right)^{\frac{1}{3}}$,

where $\rho$ is the density of the dry aerosol (assumed in SAMTOMAS as $1770 \mathrm{~kg} \mathrm{~m}^{-3}$ ). The number-median diameter $\mathrm{D}_{\mathrm{m}}$ $[\mu \mathrm{m}]$ can be calculated from

$D_{\mathrm{m}}=D_{\text {mass }} \exp \left(-1.5 \ln ^{2} \sigma_{g}\right)$,

where $\sigma_{g}$ is the geometric standard deviation of the aerosol size distribution. We choose a value of 1.4 for $\sigma_{g}$, as this was the median value found for log-normal distributions fitted to the aerosol size distributions of the training data.

\subsection{Number of new particles per $\mathrm{kg} \mathrm{SO}_{2}$ emitted}

As mentioned in Sect. 2, we have configured the SAMTOMAS model to use activation-type nucleation for this study. We would therefore expect the source of new particles to increase due to nucleation proportionally with the concentration of $\mathrm{H}_{2} \mathrm{SO}_{4}$, which should be roughly proportional to $f_{\text {ox }}$. We would therefore expect a solution that is proportional to $f_{\mathrm{ox}}$ and increases with increasing $\mathrm{bgSO}_{2}$, but not $\mathrm{SO}_{2} \mathrm{emis}$, as $N_{\text {new }}$ is normalized by the $\mathrm{SO}_{2}$ emissions. We also expect the primary loss mechanism for the newly formed particles to be coagulation with pre-existing particles, and this coagulational loss rate is roughly proportional to the condensation sink. We would therefore also expect the solution to exponentially decay with CS $\left(d / v_{g}\right)$. We find the following solution for $N_{\text {new }}$ :

$$
\begin{aligned}
& N_{\text {new }}=6.939 \times 10^{23} \\
& \frac{f_{\text {ox }}^{0.9949} \mathrm{bgSO}_{2}^{0.2500}}{\mathrm{SO}_{2} \mathrm{emis}^{0.1280}} \exp \left(-4.417 \mathrm{CS}^{0.1441}\left(\frac{d}{v_{g}}\right)^{0.1736}\right),
\end{aligned}
$$


Table 6. Quality of fit information for the P6 parameterization predicted outputs and the results of SAM-TOMAS.

\begin{tabular}{llllll}
\hline & $\begin{array}{l}\text { correlation } \\
\text { coefficient }\end{array}$ & $\begin{array}{l}\text { rms } \\
\text { error }\end{array}$ & $\begin{array}{l}\text { rms } \log _{10} \\
\text { error }\end{array}$ & $\begin{array}{l}\text { fraction within } \\
\text { a factor of } 2\end{array}$ & $\begin{array}{l}\text { fraction within } \\
\text { a factor of 10 }\end{array}$ \\
\hline$f_{\text {ox }}$ & 0.826 & 0.0190 & 0.845 & $50.3 \%$ & $77.0 \%$ \\
$M_{\mathrm{m}}$ & 0.891 & $1.38 \times 10^{-19} \mathrm{~kg}$ & 0.425 & $60.0 \%$ & $96.7 \%$ \\
$N_{\text {new }}$ & 0.670 & $\begin{array}{l}4.85 \times 10^{18} \\
\left(\mathrm{~kg} \mathrm{SO}_{2}\right)^{-1}\end{array}$ & 0.741 & $36.2 \%$ & $84.6 \%$ \\
$f_{\text {new }}$ & 0.650 & 0.289 & 1.07 & $28.6 \%$ & $66.8 \%$ \\
\hline
\end{tabular}

where the free parameters for $f_{\text {ox }}$ have been fitted to minimize the rms error in $\log _{10}\left(N_{\text {new }}\right)$, as was the case for $M_{\mathrm{m}}$ above. Similar to $M_{\mathrm{m}}$, the $\mathrm{NO}_{\mathrm{x}}$ emis scaling factor (Eq. (1)) used to calculate $f_{\text {ox }}$ in $N_{\text {new }}$ is several orders of magnitude greater than that used to calculate $f_{\text {ox }}$, as listed in Table 5. This will be discussed further in Sect. 5. We note that the P6 fit value for $N_{\text {new }}$ slightly decreases with increasing $\mathrm{SO}_{2}$ emis. As $N_{\text {new }}$ is normalized by the $\mathrm{SO}_{2}$ emissions, this is consistent with the number of new particles formed in a given plume increasing slightly less than linearly with increasing $\mathrm{SO}_{2}$ emissions.

\subsection{Fraction of sulfate mass that comprises new particles}

The mass of new particles per $\mathrm{kg} \mathrm{SO}_{2}$ emitted can be determined from the product of $M_{\mathrm{m}}$ and $N_{\text {new }}$. The product of $f_{\text {ox }}$ and $f_{\text {new }}$ also yields the mass of $\mathrm{SO}_{2}$ that ultimately forms new particles per $\mathrm{kg} \mathrm{SO}_{2}$ emitted. We therefore can calculate $f_{\text {new }}$ from the other three outputs:

$f_{\text {new }}=\frac{M_{\mathrm{m}} N_{\text {new }}}{f_{\text {ox }}} \frac{M_{\mathrm{SO}_{2}}}{M_{\mathrm{H}_{2} \mathrm{SO}_{4}}}$,

where $M_{\mathrm{SO}}$ and $M_{\mathrm{H}_{2} \mathrm{SO}_{4}}$ are the molar masses of $\mathrm{SO}_{2}$, and $\mathrm{H}_{2} \mathrm{SO}_{4}$, respectively.

However, because the fits for $M_{\mathrm{m}}, N_{\text {new }}$ and $f_{\text {ox }}$ were performed independently, this equation can yield values for $f_{\text {new }}$ greater than 1 under some conditions, which is unphysical. Under such circumstances, we reduce $M_{\mathrm{m}}$ and $N_{\text {new }}$ each by a factor of $f_{\text {new }}^{0.5}$ to maintain closure, and limit $f_{\text {new }}$ to 1 .

\section{Comparison of parameterization to full SAM-TOMAS model}

We show the correlation coefficient, rms error, rms error in the logarithm of the values, and the fraction of the training data cases within a factor of 2 or 10 for each of the outputs in Table 6. We also show the P6 predicted values against the SAM-TOMAS calculated values for $f_{\mathrm{ox}}, M_{\mathrm{m}}, N_{\text {new }}$, and $f_{\text {new }}$ in Fig. 1 . We show the values of $M_{\mathrm{m}}, N_{\text {new }}$, and $f_{\text {new }}$ only for cases where nucleation is predicted to occur.
The correlation between the P6 and SAM-TOMAS values of $f_{\text {ox }}$ is good $(R=0.826)$. The rms error is comparable to the value of $f_{\text {ox }}$ for the majority of the training cases, but this value is dominated by the small number of cases where either the P6 value, the SAM-TOMAS value, or both values of $f_{\text {ox }}$ are large. As can be seen in Fig. 1a, a large fraction (69\%) of cases have both P6 and SAM-TOMAS $f_{\text {ox }}$ less than 0.02 , and the relative error can be large for these cases, while the absolute error remains low.

The correlation between the P6 and SAM-TOMAS values of $M_{\mathrm{m}}$ is also good $(R=0.864)$. While the SAM-TOMAS values of $M_{\mathrm{m}}$ span more than five orders of magnitude, we note that the P6 values are within one order of magnitude of the SAM-TOMAS values for nearly all $(96.8 \%)$ of the training cases, and for the majority of the cases (59.5\%), they are within a factor of two. Along with the P6 and SAM-TOMAS values of $M_{\mathrm{m}}$, we also plot the values used by Dentener et al. (2006) and Adams and Seinfeld (2003) for $M_{\mathrm{m}}$ in Fig. $1 \mathrm{~b}$. We note that the value of $M_{\mathrm{m}}$ from Dentener et al. (2006) is more than three orders of magnitude larger than the largest value calculated by SAM-TOMAS for the training simulations. The value from Adams and Seinfeld (2003) is within the range of values predicted by SAM-TOMAS, but is more than two orders of magnitude larger than the median value of $M_{\mathrm{m}}$ for the training simulations. There is a large fraction of new-particle-formation cases $(40 \%)$ where both P6 and SAM-TOMAS values of $M_{\mathrm{m}}$ do not exceed $2 \times 10^{-22} \mathrm{~kg}$, corresponding to a mass mean diameter of less than $6 \mathrm{~nm}$.

While the P6 parameterization does not capture the behaviour of $N_{\text {new }}$ as well as it captures the behaviour of $f_{\text {ox }}$ and $M_{\mathrm{m}}$, the P6 values are still within one order of magnitude of the SAM-TOMAS values for most $(83.8 \%)$ of the training cases, across which the SAM-TOMAS values vary by more than six orders of magnitude. In addition to the P6 and SAMTOMAS values of $N_{\text {new }}$, we also plot the values used by Dentener et al. (2006) and Adams and Seinfeld (2003) for $N_{\text {new }}$ in Fig. 1c. We note that the value of $N_{\text {new }}$ from Dentener et al. (2006) is more than two orders of magnitude smaller than the smallest value calculated by SAM-TOMAS for the training simulations. The value from Adams and Seinfeld (2003) is within the range of values predicted by SAM-TOMAS, but is nearly one order of magnitude larger than the median value of $N_{\text {new }}$ for the training simulations. 

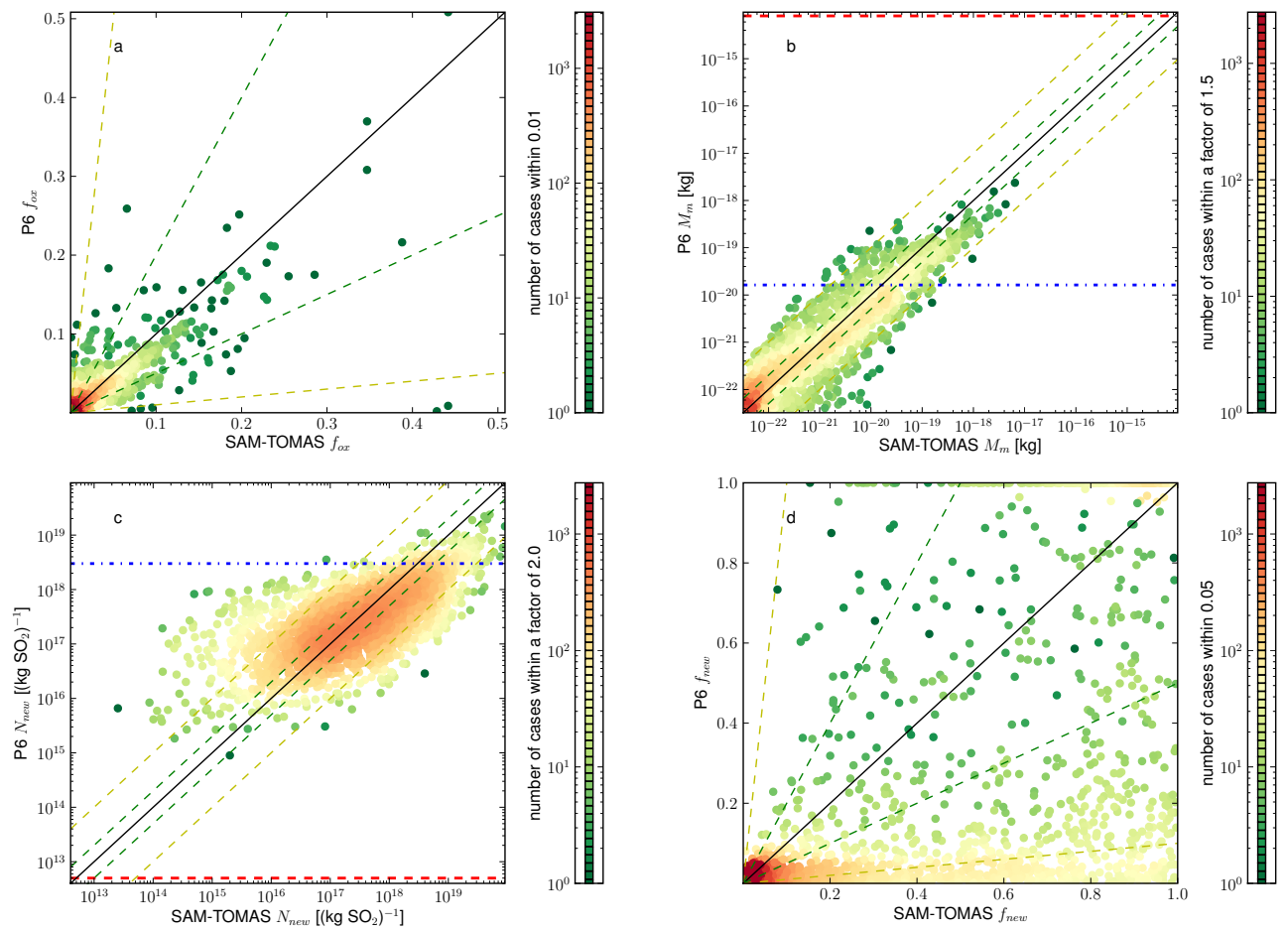

Fig. 1. P6 vs SAM-TOMAS values of $f_{o x}, M_{\mathrm{m}}, N_{\text {new }}$, and $f_{\text {new }}$. Colour of points indicates density of cases. The red dashed lines indicate the values of $M_{\mathrm{m}}$ and $N_{\text {new }}$ from Dentener et al. (2006), and the blue dash-dotted lines indicate the values of $M_{\mathrm{m}}$ and $N_{\text {new }}$ from Adams and Seinfeld (2003). The green and yellow dashed lines indicate where the predicted values are within a factor of 2 and 10 , respectively, of the calculated values.

As the P6 values of $f_{\text {new }}$ are calculated based on $f_{\text {ox }}$, $M_{\mathrm{m}}$, and $N_{\text {new }}$, instead of being fitted directly to the SAMTOMAS values, we would expect this variable to show the poorest fit to the SAM-TOMAS values. Since $f_{\text {ox }}$ and $f_{\text {new }}$ are uncorrelated, there will be instances where the value of $f_{\text {ox }}$ is small, and hence the relative error in $f_{\text {ox }}$ may be high, but the value of $f_{\text {new }}$ is not small. Since $f_{\text {new }}$ is calculated using $f_{\text {ox }}$, a large relative error in $f_{\text {ox }}$ will yield a high relative error in $f_{\text {new }}$, and so this means that the relative error in $f_{\text {new }}$ can be high, even for larger values of $f_{\text {new }}$ (hence the absolute error will also be large). However, the correlation between the P6 and SAM-TOMAS $f_{\text {new }}$ values remains good ( $R=0.667)$ largely due to resolving the cluster of values near 0 and the cluster near 1 (Fig. 1d). The P6 parameterization correctly predicts low values for $f_{\text {new }}$ for the large fraction $(56 \%)$ of training cases where the SAM-TOMAS value of $f_{\text {new }}$ is less than 0.1 , and the $\mathrm{P} 6$ value of $f_{\text {new }}$ is within 0.1 of the SAM-TOMAS value for $63.3 \%$ of the cases.

\section{Sensitivity studies}

\subsection{Sensitivities to inputs}

We show the sensitivities of $f_{\mathrm{ox}}, M_{\mathrm{m}}, N_{\text {new }}$, and $f_{\text {new }}$ to each of the P6 inputs in Figs. 2, 3, 4, and 5, respectively. Each figure shows green lines for 100 randomly chosen sets of inputs within the ranges of the training data. The black line shows the sensitivity from the set of median values for each input $\left(\mathrm{SO}_{2} \mathrm{emis}=0.1 \mathrm{~kg} \mathrm{~s}^{-1}, \mathrm{NO}_{\mathrm{x}}\right.$ emis $=0.05 \mathrm{~kg} \mathrm{~s}^{-1}$, $d=50 \mathrm{~km}$, other values shown in Tables 2 and 3). In each panel, one of the input variables is varied while the others are held fixed. In order to highlight the sensitivities to the inputs, each plotted line is shifted vertically to the centre of the subplot. For Fig. $2\left(f_{\text {ox }}\right)$ and Fig. $5\left(f_{\text {new }}\right)$, we subtract the median value of each line from its values. For Fig. $3\left(M_{\mathrm{m}}\right)$ and Fig. $4\left(N_{\text {new }}\right)$, each plotted line is divided by its median value. We do not show values for $M_{\mathrm{m}}, N_{\text {new }}$, or $f_{\text {new }}$ where nucleation is not predicted to occur by the P6 parameterization. Therefore, some lines begin or end in Figs. 3, 4, and 5 as the threshold for nucleation is crossed (Eq. 10)

The value of $f_{\text {ox }}$ (Fig. 2) is insensitive to $\mathrm{SO}_{2}$ emis, CS, and $\mathrm{bgSO}_{2}$, as one would expect. The value of $f_{\text {ox }}$ is also insensitive to $\mathrm{NO}_{\mathrm{x}}$ emis. As we note in Sect. 3.1, oxidation generally proceeds much more quickly at the plume edges and in the dilute plume than at the plume centre, so $f_{\text {ox }}$ is far more sensitive to $b g \mathrm{NO}_{\mathrm{x}}$ than to $\mathrm{NO}_{\mathrm{x}}$ emis. As BLH may only affect $f_{\text {ox }}$ in the $\mathrm{P} 6$ parameterization through the dilution of $\mathrm{NO}_{\mathrm{x}}$ emissions, $f_{\mathrm{ox}}$ is also insensitive to BLH. The value of $f_{\mathrm{ox}}$ is determined by the remaining four inputs. The value of $f_{\text {ox }}$ increases with increasing time since emission, and so nearly linearly increases with increasing $d$ and is nearly inversely proportional to $v_{g}$. The dependance of $f_{\mathrm{ox}}$ on DSWRF and 

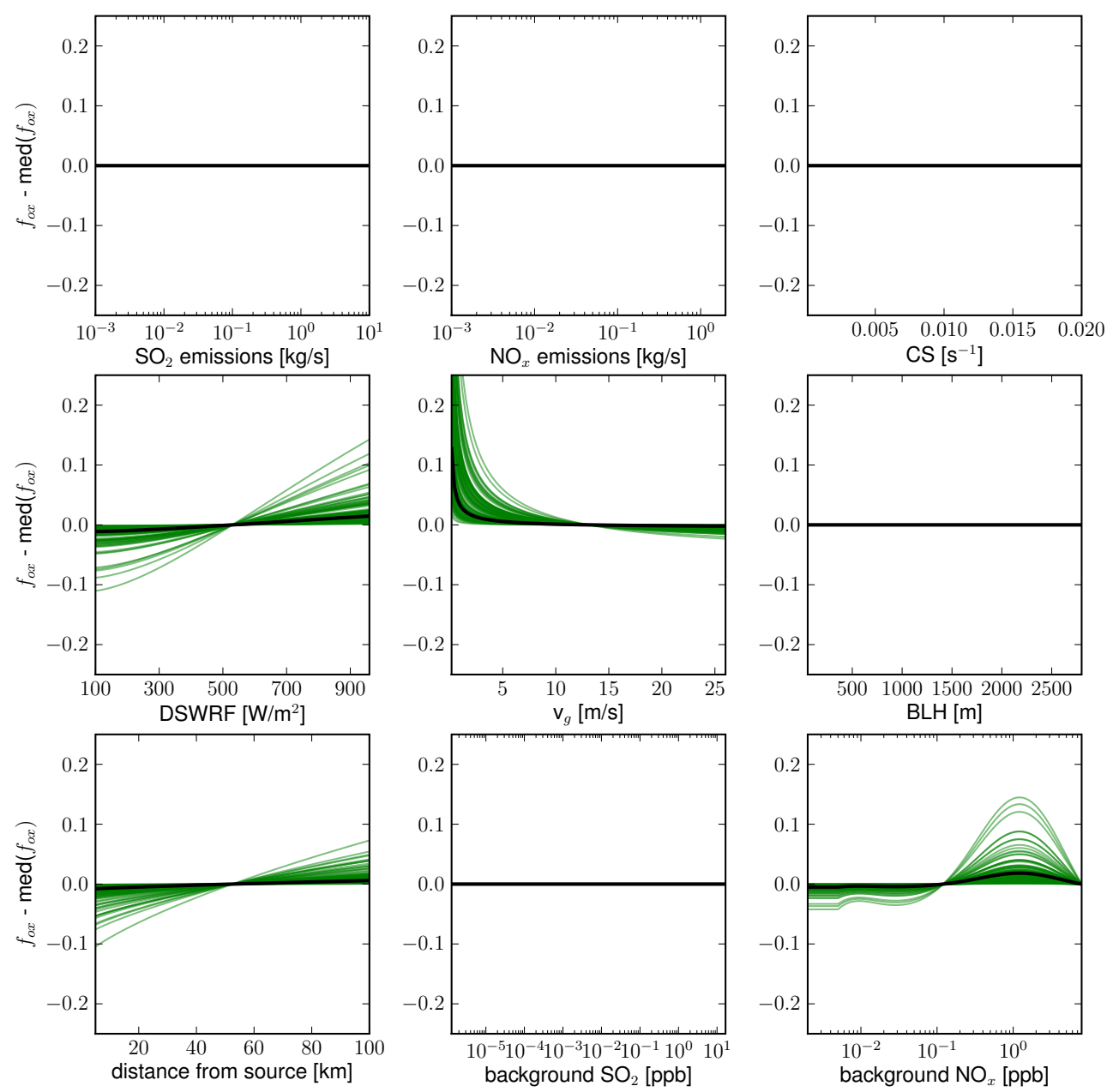

Fig. 2. Sensitivity of $f_{\text {ox }}$ to each of the inputs for 100 randomly selected sample inputs. The black line denotes the median value case. The median value of each plotted line is subtracted from its values to highlight the sensitivities to the inputs.

$\mathrm{bgNO}_{\mathrm{x}}$ is determined largely by the dependance of $\mathrm{OH}$ on these two variables, as parameterized in SAM-TOMAS. The value increases with increasing DSWRF, and there is a peak in $f_{\text {ox }}$ at bgNO $\mathrm{x}_{\mathrm{x}}$ equal to $1 \mathrm{ppb}$.

The value of $M_{\mathrm{m}}$ is much more sensitive to $\mathrm{NO}_{\mathrm{x}}$ emis than to $\mathrm{bgNO}_{\mathrm{x}}$, unlike $f_{\mathrm{ox}}$. Concentrations of $\mathrm{SO}_{2}$ are highest close to the source, so concentrations of $\mathrm{H}_{2} \mathrm{SO}_{4}$ (and particle growth rates) may also be highest close to the source, even if $\mathrm{SO}_{2}$ is being oxidized more slowly. The concentrations of $\mathrm{H}_{2} \mathrm{SO}_{4}$ close to the source will be more sensitive to $\mathrm{NO}_{\mathrm{x}}$ emissions than to background $\mathrm{NO}_{\mathrm{x}}$ concentrations, and therefore $M_{\mathrm{m}}$ is also more sensitive to $\mathrm{NO}_{\mathrm{x}}$ emis than $\mathrm{bgNO}_{\mathrm{x}}$. This is also reflected in the dependencies of $M_{\mathrm{m}}$ on $d$ and on $v_{g}$. The value of $f_{\text {ox }}$ is nearly linearly increasing with $d$, while $M_{\mathrm{m}}$ increases at low values of $d$ but becomes insensitive at higher values. The value of $M_{\mathrm{m}}$ is much less sensitive than $f_{\text {ox }}$ to $v_{g}$, although this is convoluted by the effect of $v_{g}$ on $M_{\mathrm{m}}$ through dilution of $\mathrm{SO}_{2}$ and $\mathrm{NO}_{\mathrm{x}}$ emissions, which is also the cause of the slight dependance of $M_{\mathrm{m}}$ on BLH. There is a decrease in $M_{\mathrm{m}}$ with increasing CS due to the loss in available $\mathrm{H}_{2} \mathrm{SO}_{4}$ to pre-existing particles. We also note that $M_{\mathrm{m}}$ becomes insensitive to $\mathrm{SO}_{2} \mathrm{emis}, \mathrm{bgSO}_{2}$, and $b_{\mathrm{NNO}}$, as well as $\mathrm{NO}_{\mathrm{x}}$ emis under some conditions, at small values of each of these inputs. If the background concentrations of $\mathrm{NO}_{\mathrm{x}}$ or $\mathrm{SO}_{2}$ are sufficiently low compared to emissions, in-plume $\mathrm{NO}_{\mathrm{x}}$ or $\mathrm{SO}_{2}$ will be dominated by the emissions, and so further reductions in the background concentrations will not significantly affect $M_{\mathrm{m}}$. The reverse is also true if the emissions are sufficiently low compared to the background concentrations.

The value of $N_{\text {new }}$ depends on the inputs in a similar manner to $M_{\mathrm{m}}$. It decreases with increasing CS due to both removal of new particles by coagulation and competition for available $\mathrm{H}_{2} \mathrm{SO}_{4}$. It increases with increasing DSWRF. The value of $N_{\text {new }}$ is more sensitive to $\mathrm{NO}_{\mathrm{x}}$ emis than to bgNO ${ }_{x}$. However, $N_{\text {new }}$ increases with increasing bgSO $\mathrm{gut}_{2}$ decreases with increasing $\mathrm{SO}_{2}$ emis. Increases in either emissions of $\mathrm{SO}_{2}$ or the background concentration of $\mathrm{SO}_{2}$ will 

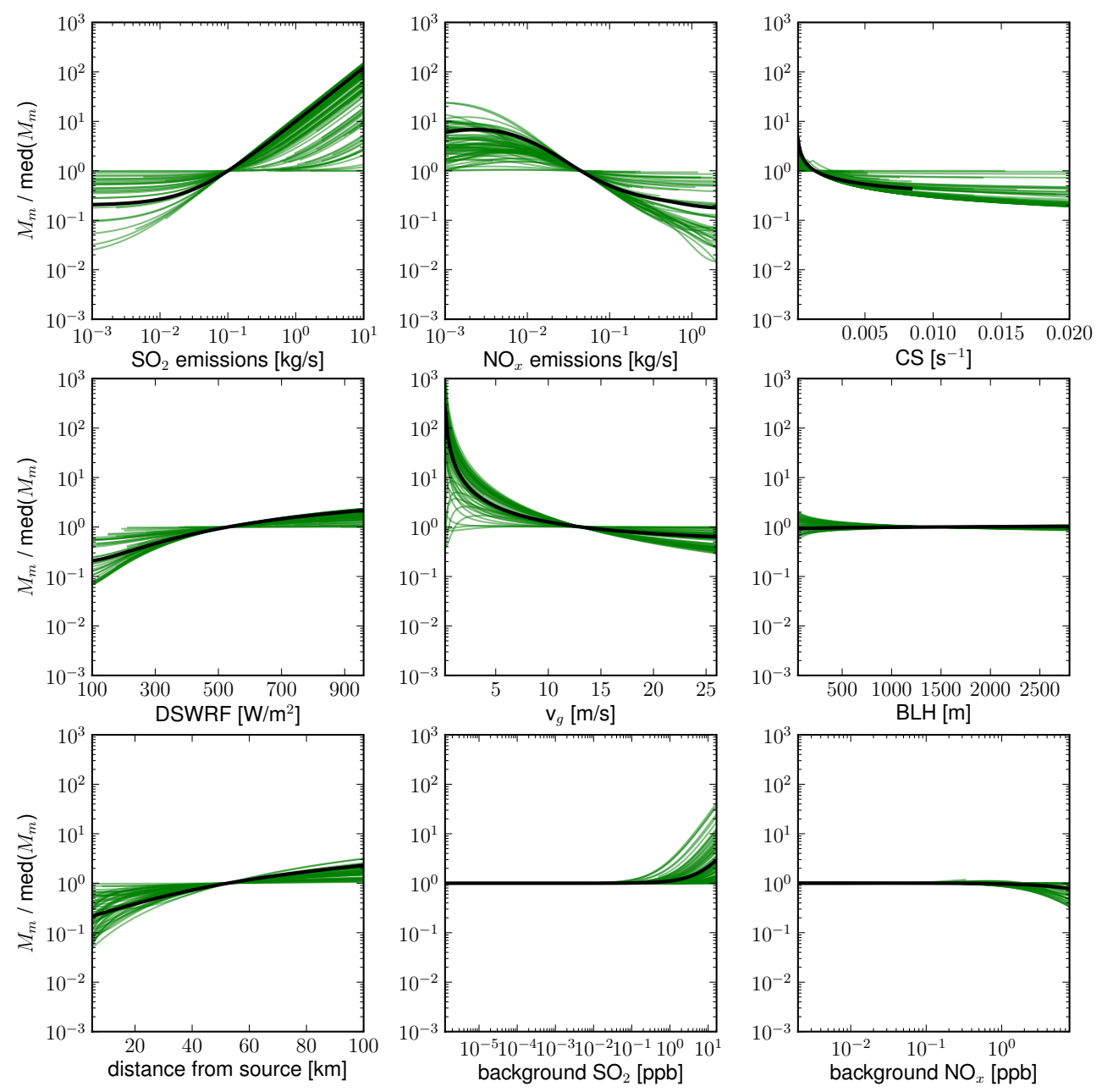

Fig. 3. Sensitivity of $M_{\mathrm{m}}$ to each of the inputs for 100 randomly selected sample inputs. If nucleation is not predicted by the P6 parameterization, no value is shown. The black line denotes the median value case. Each plotted line is divided by its median value in order to highlight the sensitivities to the inputs.

increase the available $\mathrm{H}_{2} \mathrm{SO}_{4}$, thus increasing new-particle formation, but because $N_{\text {new }}$ is defined as the number of new particles normalized by the emissions of $\mathrm{SO}_{2}$, and emissions of $\mathrm{SO}_{2}$ less than linearly increase the number of new particles, increases in the emissions of $\mathrm{SO}_{2}$ have a small decreasing effect on $N_{\text {new }}$. The value of $N_{\text {new }}$ also has a complex dependance on $v_{g}$ and $d$, either increasing or decreasing with increasing $d$ and decreasing $v_{g}$. As the time since emission $\left(d / v_{g}\right)$ increases, $N_{\text {new }}$ will increase due to continuing new-particle formation and will decrease due to coagulational scavenging by pre-existing particles. The dependance of $N_{\text {new }}$ on $d$ and $v_{g}$ will depend on the competition between these two processes. We do note, however, that $N_{\text {new }}$ tends to asymptote to a single value with increasing $d$, depending on the values of the other inputs.

Of the four outputs of the P6 parameterization, $f_{\text {new }}$ shows the most dramatic changes for small changes in some of the inputs. Specifically, $f_{\text {new }}$ is sensitive to small changes for high values of $\mathrm{SO}_{2}$ emis, high values of $\mathrm{bgSO}_{2}$, low values of CS, and, for some combinations of inputs, low values of $v_{g}$. The value of $f_{\text {new }}$ is less sensitive to the remaining variables, but increases for increasing DSWRF and $d$, decreases slightly for increasing BLH, and generally decreases with decreasing $\mathrm{bgNO}_{\mathrm{x}}$.

\subsection{Sensitivity to number of sources assumed}

Often, anthropogenic emissions inventories give emissions of $\mathrm{SO}_{2}$ and $\mathrm{NO}_{\mathrm{x}}$ on a given grid, and not per point source. Figure 6 shows the sensitivity of the P6 parameterization to assumptions about how these emissions are split between sources within the grid box. We used the P6 parameterization to predict $f_{\text {ox }}, M_{\mathrm{m}}, N_{\text {new }}$, and $f_{\text {new }}$ for 100 different sets of inputs randomly chosen from the range of values tested for each variable, assuming the emissions were split evenly amongst between 1 and 10 point sources. We also show the 

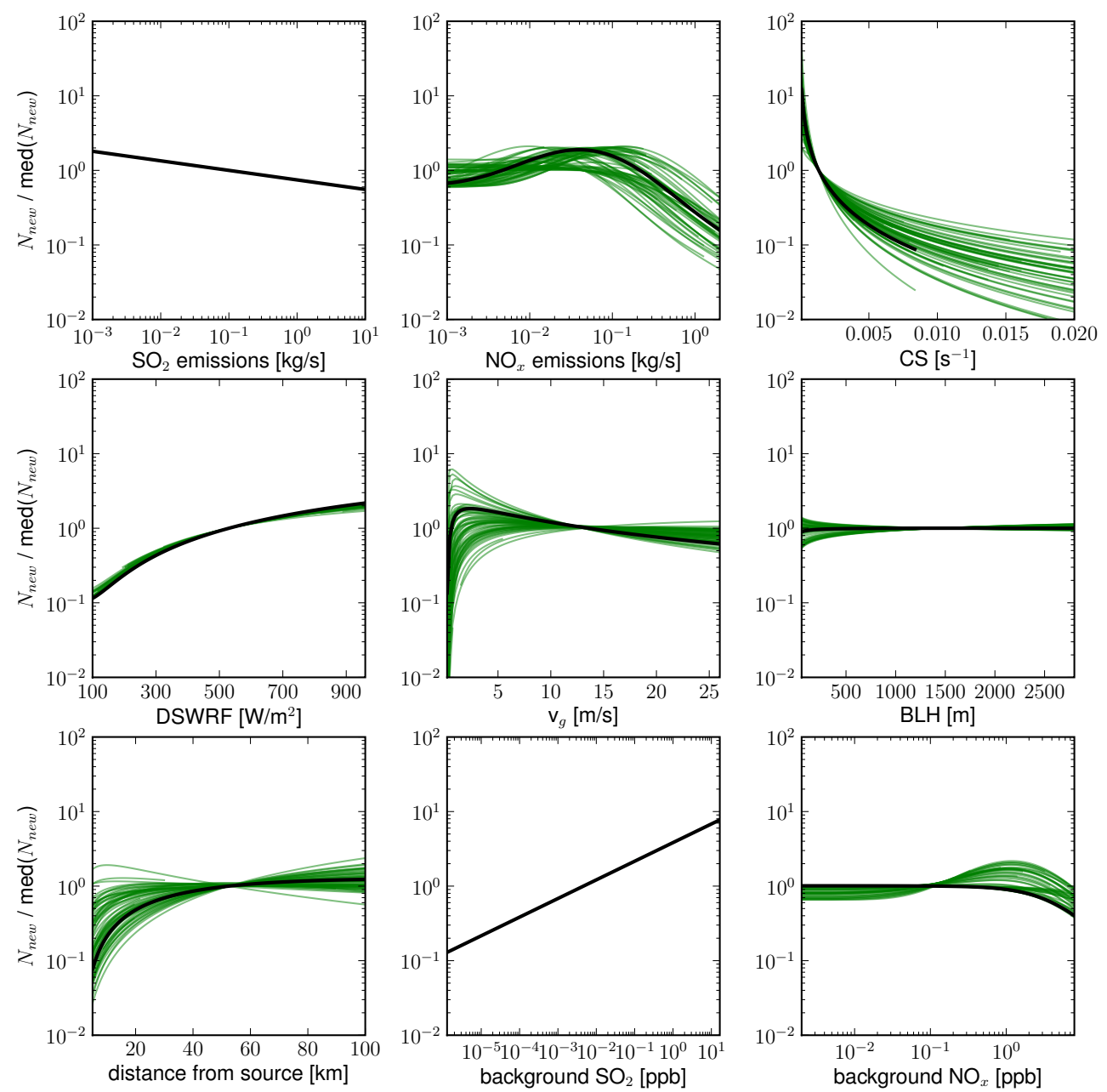

Fig. 4. Sensitivity of $N_{\text {new }}$ to each of the inputs for 100 randomly selected sample inputs. If nucleation is not predicted by the P6 parameterization, no value is shown. The black line denotes the median value case. Each plotted line is divided by its median value in order to highlight the sensitivities to the inputs.

sensitivity for the median case, as we did in Figs. 2, 3, 4, and 5. As in Figs. 2, 3, 4, and 5, we shift the lines vertically to highlight the sensitivities by subtracting the median value of each plotted line from its values for $f_{\text {ox }}$ and $f_{\text {new }}$ and dividing each plotted line by its median value for $M_{\mathrm{m}}$ and $N_{\text {new }}$. We do not show values for $M_{\mathrm{m}}, N_{\text {new }}$, and $f_{\text {new }}$ for cases where no nucleation is predicted. As the value of $f_{\text {ox }}$ is insensitive to both $\mathrm{SO}_{2}$ emis and $\mathrm{NO}_{\mathrm{x}}$ emis, it is also completely insensitive to assumptions about the number of point sources. Since $M_{\mathrm{m}}$ increases with increasing $\mathrm{SO}_{2}$ emis but decreases with increasing $\mathrm{NO}_{\mathrm{x}}$ emis across most of the ranges of these two variables, $M_{\mathrm{m}}$ may increase or decrease as the emissions are split amongst additional sources. The value of $N_{\text {new }}$ decreases with increasing $\mathrm{SO}_{2}$ emis but peaks for $\mathrm{NO}_{\mathrm{x}}$ emis values near $0.05 \mathrm{~kg} \mathrm{~s}^{-1}$, and so may also increase or decrease as $\mathrm{NO}_{\mathrm{x}}$ emis is split amongst a larger number of sources. We tested 10000 randomly generated samples within the range of inputs used for the training data, and for an increase in the number of sources from 1 to 10 , the values of $M_{\mathrm{m}}$ and $N_{\text {new }}$ stayed within a factor of 3 for 64 and $85 \%$ of the cases, respectively (note that values for $M_{\mathrm{m}}$ and $N_{\text {new }}$ span 5 and 3 orders of magnitude, so a factor of 3 change is small compared to this range). The value for $f_{\text {new }}$ can change more dramatically for large values of $\mathrm{SO}_{2}$ emis, but the change was less than \pm 0.01 for $78 \%$ of the samples tested.

As discussed earlier, we include three different options for specifying $\mathrm{SO}_{2}$ and $\mathrm{NO}_{\mathrm{x}}$ emissions in our included Fortran code of the P6 parameterization. Two of these options involve specifying the total emissions in the grid box and allowing P6 to make assumptions about the size of the sources (Table 3). Fortunately, the analysis above shows that the P6 outputs are generally not very sensitive to the number of sources assumed, so the lack of knowledge of individual sources likely will not create large errors in P6 outputs. 

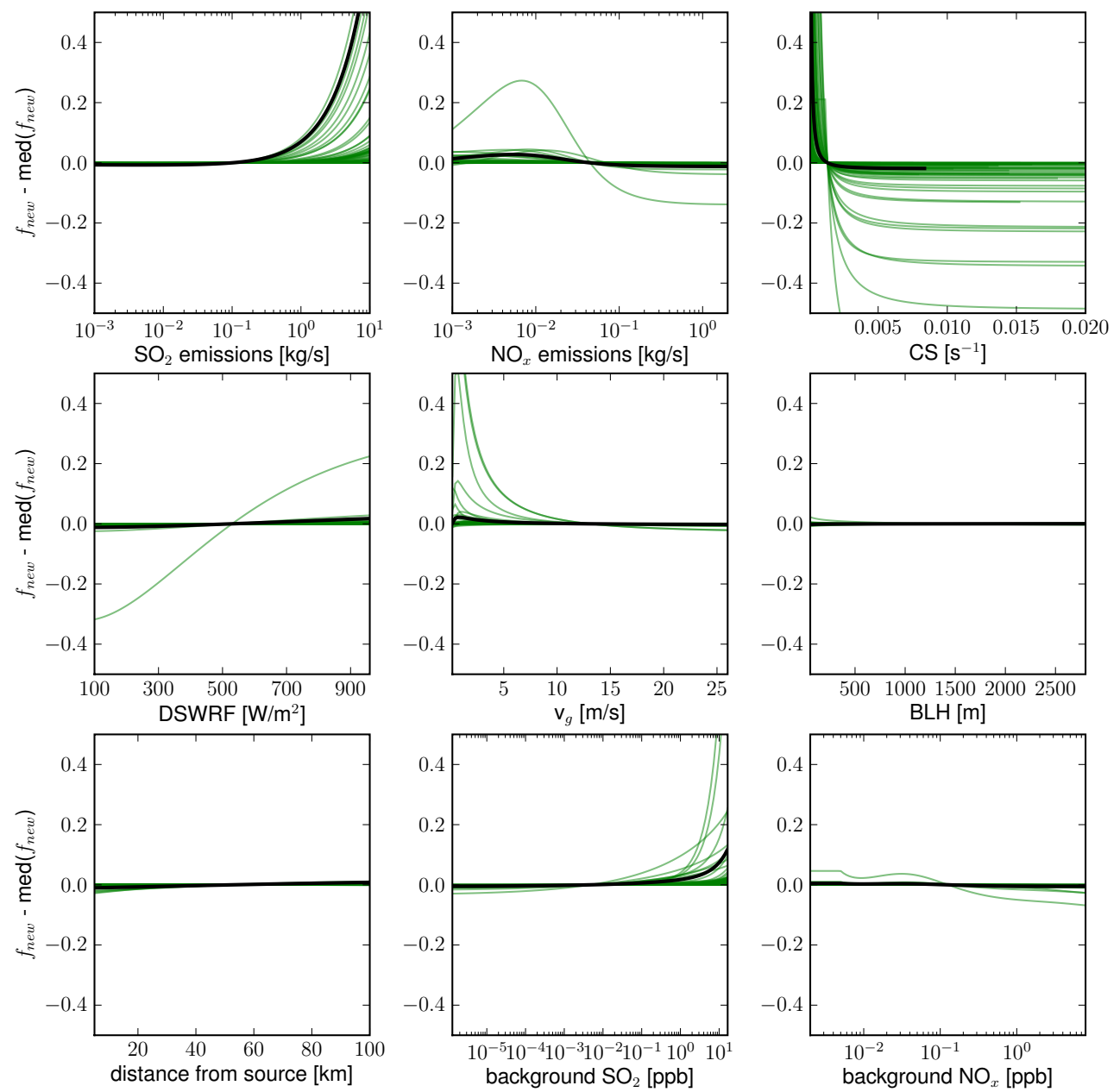

Fig. 5. Sensitivity of $f_{\text {new }}$ to each of the inputs for 100 randomly selected sample inputs. If nucleation is not predicted by the P6 parameterization, no value is shown. The black line denotes the median value case. The median value of each plotted line is subtracted from its values to highlight the sensitivities to the inputs.

\section{Conclusions}

In this study, we describe the predicting particles produced in power-plant plumes (P6) parameterization: a physically based, but computationally efficient, parameterization that predicts the characteristics of aerosol formed in sulfur-rich plumes based on variables that are commonly available in global- and regional-scale models. The parameterization predicts the fraction of the emitted $\mathrm{SO}_{2}$ that is oxidized to form $\mathrm{H}_{2} \mathrm{SO}_{4}$, the fraction of that $\mathrm{H}_{2} \mathrm{SO}_{4}$ that forms new particles, the mean mass per particle of the new particles, and the number of new particles per $\mathrm{kg} \mathrm{SO}_{2}$ emitted. It takes as inputs the source-level $\mathrm{SO}_{2}$ and $\mathrm{NO}_{\mathrm{x}}$ emissions rates, the background aerosol condensation sink, the downward shortwave radiative flux, the mean boundary-layer wind speed, the boundarylayer height, the background $\mathrm{SO}_{2}$ and $\mathrm{NO}_{\mathrm{x}}$ concentrations, and the distance from the source. The increase in running time of a 3-D aerosol model due to implementing the P6 pa- rameterization would be negligible because the parameterization consists only of several arithmetic equations.

In order to create a set of training data for the P6 parameterization, we used the SAM-TOMAS LES/CRM model with online aerosol microphysics. We have shown that the results of the parameterization show good agreement with the results of the SAM-TOMAS model and that the P6 parameterization captures the variability in aerosol formation and growth in sulfur-rich plumes, with correlation coefficients ranging from 0.650 for $f_{\text {new }}$ to 0.891 for $f_{\text {ox }}$.

While the P6 parameterization reproduces well the behaviour of the SAM-TOMAS model, we note that it inherits the limitations of the SAM-TOMAS model. Aqueousphase oxidation of $\mathrm{SO}_{2}$ is not accounted for, and therefore $f_{\text {ox }}$ may be underpredicted under cloudy conditions. Nitrous acid (HONO) and sulfur trioxide $\left(\mathrm{SO}_{3}\right)$ emission are not accounted for, and these processes may result in particle formation early in the plume. Nucleation rates are parameterized using an empirical fit proportional to $\mathrm{H}_{2} \mathrm{SO}_{4}$ concentrations. 

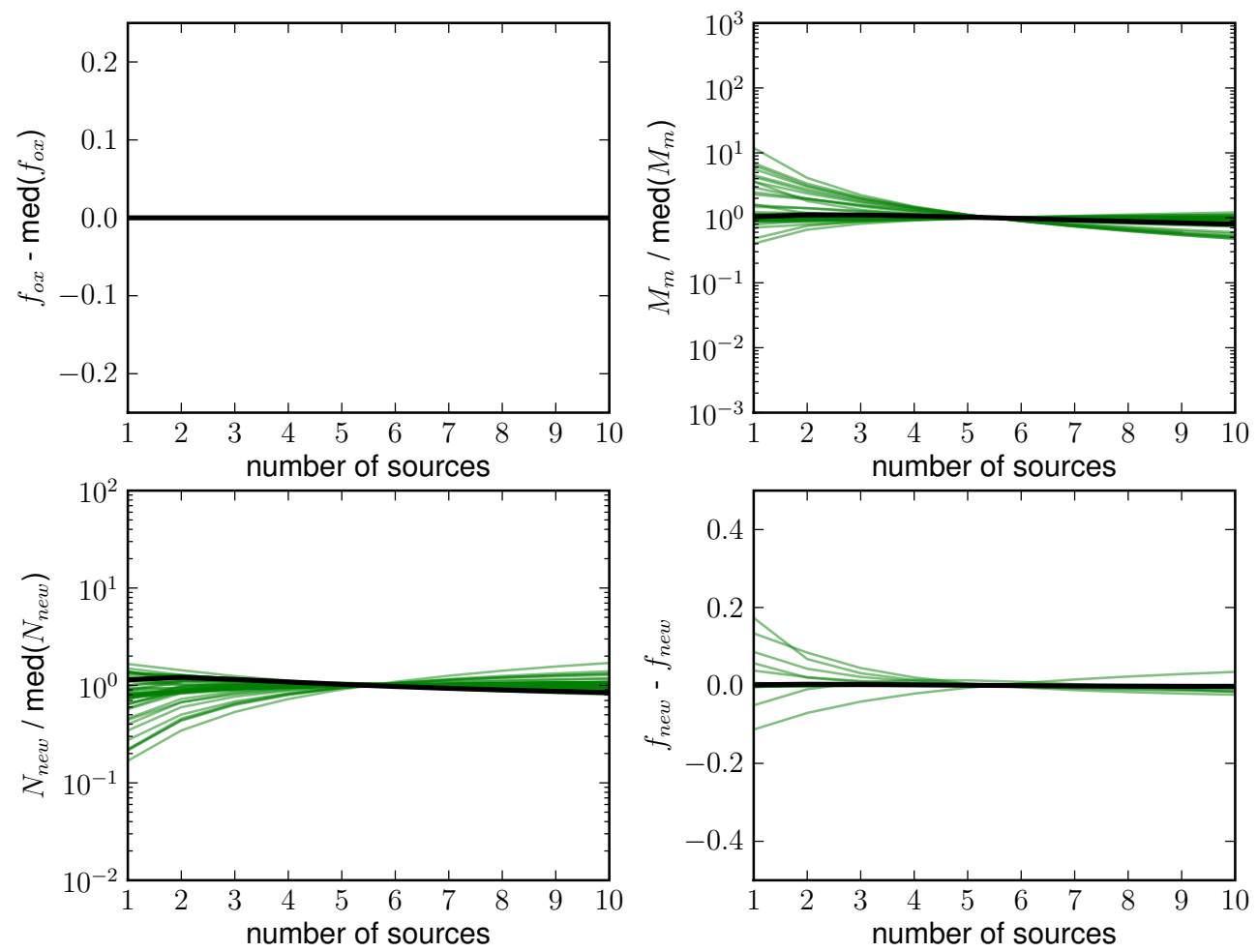

Fig. 6. Sensitivity of $f_{\mathrm{ox}}, M_{\mathrm{m}}, N_{\text {new }}$, and $f_{\text {new }}$ to the assumed number of emission sources, while keeping total emissions of $\mathrm{SO}_{2}$ and $\mathrm{NO}_{x}$ constant, for 100 randomly selected sets of inputs. If nucleation is not predicted by the P6 parameterization, no value is shown. The black line in each figure denotes the median value case. In order to highlight the sensitivities to the number of sources assumed, for $f_{\text {ox }}$ and $f_{\text {new }}$, the median value of each plotted line is subtracted from the line, and for $M_{\mathrm{m}}$ and $N_{\text {new }}$, each plotted line is divided by its median value.

Despite these limitations, the SAM-TOMAS model has been previously shown to well represent the formation and growth of aerosol in coal-fired power-plant plumes (Stevens et al., 2012; Lonsdale et al., 2012). We therefore believe that the P6 parameterization captures well the variability in new-particle formation and growth within sulfur-rich plumes.

The median value of $f_{\text {ox }}$ predicted by the $\mathrm{P} 6$ parameterization (0.0098) for the training cases is much less than the fraction of emitted $\mathrm{SO}_{2}$ mass added as sub-grid sulfate by Adams and Seinfeld (2003) (0.03) or Dentener et al. (2006) (0.025). Additionally, we excluded night-time cases from our training data, where no oxidation of $\mathrm{SO}_{2}$ and no new-particle formation would be predicted by the P6 parameterization. Consequently, we expect that predictions of total aerosol mass near sulfur-rich point sources using global-scale models implementing the P6 parameterization will be less than those using the Adams and Seinfeld (2003) or Dentener et al. (2006) assumptions. Additionally, as the median values of both $N_{\text {new }}$ and $M_{\mathrm{m}}$ predicted by SAM-TOMAS were less than those predicted by Adams and Seinfeld (2003), we expect than both globally averaged aerosol number concentrations and globally averaged CCN concentrations would be less than those using the Adams and Seinfeld (2003) assumption, with large regional differences (e.g. less $\mathrm{CCN}$ formation using the P6 parameterization under cloudy, polluted conditions than sunny, low-background-aerosol conditions). It is our intent to perform a complete comparison of the results of a global chemical-transport model with and without the parameterization as a future work.

This parameterization will allow for improved representation of sub-grid formation and growth of sulfate aerosol in global- and regional-scale models, allowing for more accurate predictions of aerosol size distributions and improved confidence in studies of aerosol effects on health and climate.

\section{Appendix A}

\section{What if one or more of the P6 inputs are not available?}

$\mathrm{SO}_{2}$ emis, $\mathrm{NO}_{\mathrm{x}}$ emis: if no estimate of the $\mathrm{SO}_{2}$ emissions is available, the P6 parameterization can be run assuming a representative distribution of power plants within the area. This is described in more detail in Sect. 3. If the total $\mathrm{NO}_{\mathrm{x}}$ emissions are unknown, the parameterization will assume a $\mathrm{SO}_{2}$ emis : $\mathrm{NO}_{\mathrm{X}}$ emis ratio of 0.419 based on the $2010 \mathrm{CAM}$ data.

DSWRF: the clear-sky. DSWRF can be calculated by

dswrf $=S_{0} T \cos ($ sza) 
where $S_{0}$ is the solar constant at the top of the atmosphere, $1370 \mathrm{~W} \mathrm{~m}^{-2}, T$ is the transmittance of the atmosphere, and sza is the solar zenith angle. The clear-sky transmittance has a value of about 0.76 (globally averaged; Seinfeld and Pandis, 2006), and the solar zenith angle can be calculated based on the latitude, longitude, time of day, and day of year. This approximation will typically overestimate DSWRF as it assumes no cloud cover. If no input is given, a value of $400 \mathrm{~W} \mathrm{~m}^{-2}$ will be assumed.

CS: the value of CS can be approximated based on a typical aerosol background for the location in question. We note that the typical aerosol size distributions listed in Seinfeld and Pandis (2006) for urban, rural, remote continental, and marine conditions correspond to condensation sinks of 0.060 , $0.0063,0.011$, and $0.0010 \mathrm{~s}^{-1}$, respectively. Also, the remote continental size distribution yields a $\mathrm{PM}_{10}$ mass concentration of $25.88 \mu \mathrm{g} \mathrm{m}^{-3}$, so we suggest that CS may be estimated from $\mathrm{PM}_{10}$ mass concentrations by multiplying by $4.3 \times 10^{-4} \mathrm{~s}^{-1} /\left(\mu \mathrm{g} \mathrm{m}^{-3}\right)$. If no input is given, we will assume the value for a remote continental case, $0.011 \mathrm{~s}^{-1}$.

$v_{g}$ : the value of $v_{g}$ must be assumed if not known. We choose a typical value of $6 \mathrm{~m} \mathrm{~s}^{-1}$ if no input is given.

BLH: the BLH can be approximated by typical values for the location and time of day. If no value is given, a value of $500 \mathrm{~m}$ will be assumed.

$d$ : we recognize that there is some ambiguity about what value should be used as input for $d$ by global- and regionalscale model users. One interpretation is that $d$ is the distance where the air mass passing over the source enters the next adjacent grid cell. Another is the distance where the width of the plume equals the grid width, allowing the plume to be resolved. However, solving for either of these distances under changing wind direction and meteorological conditions is not a trivial task even if the location of the power plant within the grid cell is known, and often the location will not be available. We suggest then that users of our parameterization use half the horizontal grid cell resolution as an approximation for $d$. We show in our sensitivity studies that for distances greater than $30 \mathrm{~km}, M_{\mathrm{m}}, N_{\text {new }}$, and $f_{\text {new }}$ are not strongly dependant on $d$, and $f_{\text {ox }}$ is a less-than-linear function of $d$.

$\mathrm{bgSO}_{2}, \mathrm{bgNO}_{\mathrm{x}}$ : following Table 2.7 of Seinfeld and Pandis (2006), we suggest values of $\mathrm{bgNO}_{\mathrm{x}}$ of $10 \mathrm{ppb}$ for urban locations, $1 \mathrm{ppb}$ for rural locations, and $0.05 \mathrm{ppb}$ for remote locations. For $\mathrm{bgSO}_{2}$ we suggest values of $10 \mathrm{ppb}$ for urban locations, $0.5 \mathrm{ppb}$ for remote continental conditions, and $0.05 \mathrm{ppb}$ for marine conditions. If no input is given, values of 0.5 and $1 \mathrm{ppb}$ are used for $\mathrm{bgSO}_{2}$ and $\mathrm{bgNO}_{\mathrm{x}}$.

\section{Appendix B}

\section{Summary of equations necessary for each output}

We note that the full parameterization is available programmed in Fortran 90 as a supplement. However, if the pro- vided code is insufficient for the users' needs, we request that the users contact the authors to find out if the P6 parameterization has already been translated into the necessary programming language, if the necessary adjustments have already been made, or if an updated version is available. In the case where this still proves insufficient, we summarize in this appendix which equations from the preceding manuscript are necessary to calculate each output. We strongly recommend that users consult the preceding manuscript for a full discussion of caveats and assumptions associated with the P6 parameterization. We also recommend that users ensure that they use the correct value from Table 5 whenever they use Eq. (1) or Eq. (9).

\section{Fraction of $\mathrm{SO}_{2}$ oxidized $\left(f_{\text {ox }}\right)$ :}

Equations 1-6, 8 (2nd row from Table 5).

\section{Nucleation:}

Equations 1, 9, 10 (3rd row from Table 5).

\section{Mean mass of new particles $\left(M_{m}\right)$ :}

First, determine if significant nucleation has occurred $\left(M_{\mathrm{m}}\right.$ is poorly defined otherwise):

Equations 1, 9, 10 (3rd row from Table 5).

Then calculate $f_{\text {ox,eff }}$ : Eqs. 1-6, 8 (4th row from Table 5).

Then Eq. 11.

If also using $f_{\text {new }}$, calculate it now as noted below. If $f_{\text {new }}>1$, divide $M_{\mathrm{m}}$ by $f_{\text {new }}^{0.5}$ to maintain closure.

\section{Median diameter of new particles $\left(D_{m}\right)$ :}

Calculate $M_{\mathrm{m}}$ as noted above. Then Eqs. 12, 13 .

\section{Number of new particles per $\mathrm{kg} \mathrm{SO} \mathrm{O}_{2}\left(\mathrm{~N}_{\text {new }}\right)$ :}

First, determine if significant nucleation has occurred $\left(N_{\text {new }}\right.$ very small otherwise):

Equations (1), (9), (10) (3rd row from Table 5).

Then calculate $f_{\text {ox,eff }}$ : Eqs. (1)-(6), (8) (4th row from Table 5).

Then Eq. (11).

If also using $f_{\text {new }}$, calculate it now as noted below. If $f_{\text {new }}$ $>1$, divide $N_{\text {new }}$ by $f_{\text {new }}^{0.5}$ to maintain closure.

\section{Fraction of sulfate mass that comprises new particles $\left(f_{\text {new }}\right)$ :}

Calculate $f_{\text {ox }}, M_{\mathrm{m}}$, and $N_{\text {new }}$ as noted above. Then use Eq. 15. 


\section{Supplementary material related to this article is available online at http://www.atmos-chem-phys.net/13/ 12117/2013/acp-13-12117-2013-supplement.zip.}

Acknowledgements. We thank the Atlantic Computational Excellence Network (ACENet) for the computational resources used in this study. We also thank the Natural Sciences and Engineering Research Council (NSERC) of Canada for funding.

Edited by: D. Topping

\section{References}

Adams, P. J. and Seinfeld, J. H.: Predicting global aerosol size distributions in general circulation models, J. Geophys. Res., 107, 1-23, doi:10.1029/2001JD001010, 2002.

Adams, P. J. and Seinfeld, J. H.: Disproportionate impact of particulate emissions on global cloud condensation nuclei concentrations, Geophys. Res. Lett., 30, 1239, doi:10.1029/2002GL016303, 2003.

Albrecht, B.: Aerosols, cloud microphysics, and fractional cloudiness., Science, New York, NY, 245, 1227-1230, 1989.

Bey, I., Jacob, D. J., Yantosca, R. M., Logan, J. a., Field, B. D., Fiore, A. M., Li, Q., Liu, H. Y., Mickley, L. J., and Schultz, M. G.: Global modeling of tropospheric chemistry with assimilated meteorology: Model description and evaluation, J. Geophys. Res., 106, 23073, doi:10.1029/2001JD000807, 2001.

Charlson, R. J., Schwartz, S. E., Hales, J. M., Cess, R. D., Coakley, J. a, Hansen, J. E., and Hofmann, D. J.: Climate forcing by anthropogenic aerosols, Science, New York, NY, 255, 423-430, doi:10.1126/science.255.5043.423, 1992.

Dentener, F., Kinne, S., Bond, T., Boucher, O., Cofala, J., Generoso, S., Ginoux, P., Gong, S., Hoelzemann, J. J., Ito, A., Marelli, L., Penner, J. E., Putaud, J. P., Textor, C., Schulz, M., Van Der Werf, G. R., and Wilson, J.: Emissions of primary aerosol and precursor gases in the years 2000 and 1750 prescribed data-sets for AeroCom, Atmos. Chem. Phys., 6, 4321-4344, doi:10.5194/acp-64321-2006, 2006.

Dockery, D., Pope, C., Xu, X., Spengler, J. D., Ware, J. H., Fay, M. E., Ferris, B. G., and Speizer, F. E.: An association between air pollution and mortality in six US cities, New England Journal of Medicine, 329(24), 1753-1759, doi:10.1056/NEJM199312093292401, 1993.

Dusek, U., Frank, G. P., Hildebrandt, L., Curtius, J., Schneider, J., Walter, S., Chand, D., Drewnick, F., Hings, S., Jung, D., Borrmann, S., and Andreae, M. O.: Size matters more than chemistry for cloud-nucleating ability of aerosol particles, Science New York, NY, 312, 1375-1378, doi:10.1126/science.1125261, 2006.

Forster, P., Ramaswamy, V., Artaxo, P., Berntsen, T., Betts, R., Fahey, D. W., Haywood, J., Lean, J., Lowe, D. C., Myhre, G., Nganga, J., Prinn, R., Raga, G., Schulz, M., and Dorland, R. V.: Changes in Atmospheric Constituents and in Radiative Forcing, in Climate Change 2007: The Physical Science Basis, Contribution of Working Group I to the Fourth Assessment Report of the Intergovernmental Panel on Climate Change, edited by: Miller, H. L., 129-234, Cambridge University Press, Cambridge, UK and New York, NY, USA, 2007.
Kerminen, V., Lehtinen, K., Anttila, T., and Kulmala, M.: Dynamics of atmospheric nucleation mode particles: a timescale analysis, Tellus B, 56, 135-146, 2004.

Khairoutdinov, M. and Randall, D.: Cloud resolving modeling of the ARM summer 1997 IOP: Model formulation, results, uncertainties, and sensitivities, Journal of the Atmospheric Sciences, 60, 607-626, doi:10.1175/15200469(2003)060<0607:CRMOTA>2.0.CO;2, 2003.

Kulmala, M. and Kerminen, V.-M.: On the formation and growth of atmospheric nanoparticles, Atmos. Res., 90, 132-150, doi:10.1016/j.atmosres.2008.01.005, 2008.

Kulmala, M., Lehtinen, K. and Laaksonen, A.: Cluster activation theory as an explanation of the linear dependence between formation rate of $3 \mathrm{~nm}$ particles and sulphuric acid concentration, Atmos. Chem. Phys., 6, 787-793, doi:10.5194/acpd-6-787-2006, 2006.

Lee, L. A., Pringle, K. J., Reddington, C. L., Mann, G. W., Stier, P., Spracklen, D. V., Pierce, J. R., and Carslaw, K. S.: The magnitude and causes of uncertainty in global model simulations of cloud condensation nuclei, Atmos. Chem. Phys., 13, 8879-8914, doi:10.5194/acp-13-8879-2013, 2013.

Lonsdale, C. R., Stevens, R. G., Brock, C. A., Makar, P. A., Knipping, E. M., and Pierce, J. R.: The effect of coal-fired powerplant $\mathrm{SO}_{2}$ and $\mathrm{NO}_{\mathrm{x}}$ control technologies on aerosol nucleation in the source plumes, Atmos. Chem. Phys., 12, 11519-11531, doi:10.5194/acp-12-11519-2012, 2012.

Luo, G. and Yu, F.: Sensitivity of global cloud condensation nuclei concentrations to primary sulfate emission parameterizations, Atmos. Chem. Phys., 11, 1949-1959, doi:10.5194/acp-111949-2011, 2011.

Makkonen, R., Asmi, a., Korhonen, H., Kokkola, H., Järvenoja, S., Räisänen, P., Lehtinen, K. E. J., Laaksonen, a., Kerminen, V.M., Järvinen, H., Lohmann, U., Bennartz, R., Feichter, J., and Kulmala, M.: Sensitivity of aerosol concentrations and cloud properties to nucleation and secondary organic distribution in ECHAM5-HAM global circulation model, Atmos. Chem. Phys., 9, 1747-1766, doi:10.5194/acp-9-1747-2009, 2009.

Mauldin, R. L., Berndt, T., Sipilä, M., Paasonen, P., Petäjä, T., Kim, S., Kurtén, T., Stratmann, F., Kerminen, V.-M., and Kulmala, M.: A new atmospherically relevant oxidant of sulphur dioxide., Nature, 488, 193-196, doi:10.1038/nature11278, 2012.

Mesinger, F., DiMego, G., Kalnay, E., Mitchell, K., Shafran, P. C., Ebisuzaki, W., Jovic', D., Woollen, J., Rogers, E., Berbery, E. H., Ek, M. B., Fan, Y., Grumbine, R., Higgins, W., Li, H., Lin, Y., Manikin, G., Parrish, D., and Shi, W.: North American Regional Reanalysis, B. Am. Meteor. Soc., 87, 343-360, doi:10.1175/BAMS-87-3-343, 2006.

Olson, J. R., Crawford, J. H., Chen, G., Brune, W. H., Faloona, I. C., Tan, D., Harder, H., and Martinez, M.: A reevaluation of airborne $\mathrm{HO}$ x observations from NASA field campaigns, J. Geophys. Res., 111, D10301, doi:10.1029/2005JD006617, 2006.

Peters, A., Wichmann, H. E., Tuch, T., Heinrich, J. and Heyder, J.: Respiratory effects are associated with the number of ultrafine particles, Am. J. Resp. Crit. Care Med., 155, 1376-1383, 1997.

Pierce, J. R. and Adams, P. J.: Global evaluation of CCN formation by direct emission of sea salt and growth of ultrafine sea salt, J. Geophys. Res., 111, D06203, doi:10.1029/2005JD006186, 2006.

Pierce, J. R. and Adams, P. J.: Uncertainty in global CCN concentrations from uncertain aerosol nucleation and primary emission 
rates, Atmos. Chem. Phys., 9, 1339-1356, doi:10.5194/acp-91339-2009, 2009.

Pierce, J. R., Chen, K. and Adams, P. J.: Contribution of primary carbonaceous aerosol to cloud condensation nuclei: processes and uncertainties evaluated with a global aerosol microphysics model, Atmos. Chem. Phys., 7(20), 5447-5466, doi:10.5194/acp-7-5447-2007, 2007.

Pierce, J. R., Evans, M. J., Scott, C. E., D’Andrea, S. D., Farmer, D. K., Swietlicki, E., and Spracklen, D. V.: Weak global sensitivity of cloud condensation nuclei and the aerosol indirect effect to Criegee $+\mathrm{SO}_{2}$ chemistry, Atmos. Chem. Phys., 13, 3163-3176, doi:10.5194/acp-13-3163-2013, 2013.

Seinfeld, J. H. and Pandis, S. N.: Atmos. Chem. Phys.: From Air Pollution to Climate Change, 2nd ed., John Wiley and Sons, Inc., Hoboken, New Jersey, p. 371 and p. 1069, 2006.

Snow-Kropla, E. J., Pierce, J. R., Westervelt, D. M., and Trivitayanurak, W.: Cosmic rays, aerosol formation and cloudcondensation nuclei: sensitivities to model uncertainties, Atmos. Chem. Phys., 11, 4001-4013, doi:10.5194/acp-11-4001-2011, 2011.

Spracklen, D. V., Pringle, K. J., Carslaw, K. S., Chipperfield, M. P., and Mann, G. W.: A global off-line model of sizeresolved aerosol microphysics: I. Model development and prediction of aerosol properties, Atmos. Chem. Phys., 5, $2227-$ 2252, doi:10.5194/acp-5-2227-2005, 2005.

Stevens, R. G., Pierce, J. R., Brock, C. A., Reed, M. K., Crawford, J. H., Holloway, J. S., Ryerson, T. B., Huey, L. G., and Nowak, J. B.: Nucleation and growth of sulfate aerosol in coal-fired power plant plumes: sensitivity to background aerosol and meteorology, Atmos. Chem. Phys., 12, 189-206, doi:10.5194/acp12-189-2012, 2012.
Trivitayanurak, W., Adams, P. J., Spracklen, D. V., and Carslaw, K. S.: Tropospheric aerosol microphysics simulation with assimilated meteorology: model description and intermodel comparison, Atmos. Chem. Phys., 8, 3149-3168, doi:10.5194/acp-83149-2008, 2008.

Twomey, S.: Pollution and planetary albedo, Atmos. Environ., 8, 1251-1256, doi:10.1016/0004-6981(74)90004-3, 1974.

United States Environmental Protection Agency: Clean Air Markets: Data and Maps, available at: http://ampd.epa.gov/ampd/ (last access: March 2013), 2012.

Wang, M. and Penner, J. E.: Aerosol indirect forcing in a global model with particle nucleation, Atmos. Chem. Phys., 9, 239-260, doi:10.5194/acp-9-239-2009, 2009.

Yu, F.: Diurnal and seasonal variations of ultrafine particle formation in anthropogenic SO2 plumes., Environ. Sci. Technol., 44 2011-2015, doi:10.1021/es903228a, 2010.

Yu, F. and Luo, G.: Simulation of particle size distribution with a global aerosol model: contribution of nucleation to aerosol and CCN number concentrations, Atmos. Chem. Phys., 9, 76917710, doi:10.5194/acp-9-7691-2009, 2009.

Zhou, W., Cohan, D. S., Pinder, R. W., Neuman, J. A., Holloway, J. S., Peischl, J., Ryerson, T. B., Nowak, J. B., Flocke, F., and Zheng, W. G.: Observation and modeling of the evolution of Texas power plant plumes, Atmos. Chem. Phys., 12, 455-468, doi:10.5194/acp-12-455-2012, 2012. 